\title{
THE
}

\section{Local ocean response to a multiphase westerly wind burst: 2 . Thermal and freshwater responses}

\author{
W. D. Smyth \\ David L. Hebert \\ University of Rhode Island, davidhebert@uri.edu \\ J. N. Moum
}

Follow this and additional works at: https://digitalcommons.uri.edu/gsofacpubs

Terms of Use

All rights reserved under copyright.

\section{Citation/Publisher Attribution}

Smyth, W. D., D. Hebert, and J. N. Moum (1996), Local ocean response to a multiphase westerly wind burst: 2. Thermal and freshwater responses, J. Geophys. Res., 101(C10), 22513-22533, doi: 10.1029/ 96JC02006.

Available at: https://doi.org/10.1029/96JC02006

This Article is brought to you for free and open access by the Graduate School of Oceanography at DigitalCommons@URI. It has been accepted for inclusion in Graduate School of Oceanography Faculty Publications by an authorized administrator of DigitalCommons@URI. For more information, please contact digitalcommons-group@uri.edu. 


\title{
Local ocean response to a multiphase westerly wind burst
}

\section{Thermal and freshwater responses}

\author{
W. D. Smyth \\ College of Oceanic and Atmospheric Sciences, Oregon State University, Corvallis \\ D. Hebert \\ Graduate School of Oceanography, University of Rhode Island, Narragansett
}

\author{
J. N. Moum \\ College of Oceanic and Atmospheric Sciences, Oregon State University, Corvallis
}

\begin{abstract}
A westerly wind burst observed in the warm pool of the western equatorial Pacific Ocean cooled the ocean's surface layer by about $0.8^{\circ} \mathrm{C}$. Turbulent entrainment at the base of this layer caused cooling but also heating due to the reversal of the vertical temperature gradient during rain events. Consequently, the cumulative effect of turbulent entrainment was minimized. Following the wind burst, a sustained eastward surface current contributed to high current shear and turbulent dissipation rates at the top of the thermocline. As a result, most of the heat transfer into the thermocline occurred after the wind burst had ended. The cruise-averaged turbulent flux into the thermocline was $17 \pm 10 \mathrm{~W} \mathrm{~m}^{-2}$, which suggests that the annual mean is only a few watts per square meter. The restratification of the upper ocean in the aftermath of the wind burst is accounted for partly (but not wholly) by local turbulent entrainment. Despite heavy precipitation, upper ocean salinity generally increased during the cruise. Advection appears to have been the dominant factor governing local salinity changes.
\end{abstract}

\section{Introduction}

Efforts to understand and model interannual sea surface temperature (SST) evolution in the tropical Pacific depend on accurate knowledge of heat exchanges with the atmosphere. An error as small as $10 \mathrm{~W} \mathrm{~m}^{-2}$ in the annual mean surface heat flux can cause model SST to drift by $1^{\circ} \mathrm{C}$ in a year [Gent, 1991]. Estimates of the annual mean heat flux into the western tropical Pacific have varied by amounts much greater than this, ranging from near 0 [Gent, 1991] to $70 \mathrm{~W} \mathrm{~m}^{-2}$ [Reed, 1985]. Heat budget considerations suggest that the smaller estimates are more likely to be accurate. Because mean currents and lateral gradients are weak in this region, it has been suggested that most of the heat flux input at the surface must ultimately be balanced by turbulent mixing of heat into the thermocline [Niiler and Stevenson, 1982], and the prevalence of stable salt stratification above the thermocline suggests that this turbulent heat flux is small [Lukas and Lindstrom, 1987, 1991]. An early attempt to estimate the turbulent heat flux

Copyright 1996 by the American Geophysical Union.

Paper number 96JC02006.

0148-0227/96/96JC-02006\$09.00 into the thermocline [Godfrey and Lindstrom, 1989] has yielded the relatively small value of $10 \mathrm{~W} \mathrm{~m}^{-2}$, providing observational support for Lukas and Lindstrom's hypothesis.

A possible exception to this scenario occurs during westerly wind bursts (WWBs), as intense surface forcing generates deep mixing. Over the course of a typical year, several wind bursts occur and may generate enough heat flux into the thermocline to make the annual mean value significantly nonzero. If this were the case, a larger mean surface flux could be sustained.

During the intensive observation period (IOP) of the Tropical Ocean-Global Atmosphere-Coupled Ocean Atmosphere Response Experiment (TOGA-COARE), microstructure measurements designed to yield estimates of the turbulent heat flux were made in concert with measurements of the various components of the surface heat flux. The IOP encompassed both a multiphase westerly wind burst and calm conditions more representative of the local climatology. As a result, it should be possible to sharpen estimates of the annual means of both the surface flux and the flux into the thermocline.

Our purpose here is to report on observations made at a fixed point near the center of the warm pool $\left(1^{\circ} 45^{\prime} \mathrm{S}\right.$, $156^{\circ} \mathrm{E}$ ) between December 20, 1992, and January 12, 1993. Meteorology during this interval was dominated 
by a three-phase westerly wind burst. In a companion paper [Smyth et al., this issue] (hereinafter referred to as SHM1), we describe the dynamic component of the ocean's response to the wind burst. In this paper, we address the thermal and freshwater responses. Our primary goal is to evaluate the subsurface processes which govern the response of SST and sea surface salinity (SSS) to the surface forcing associated with the wind burst. We present detailed estimates of the turbulent heat flux into the thermocline and will see that this flux is too small to be consistent with a large annual mean surface value. We will also use estimates of the turbulent flux made relatively near the surface, together with estimates of the subsurface radiative heat flux based on the measurements of Siegel et al. [1995], to construct a heat budget for the diurnal mixed layer. This will provide both an additional check on the accuracy of the measured fluxes and new insight into the roles of the subsurface heat fluxes in modulating the response of SST to surface forcing.

We begin in section 2 by examining the depths over which surface inputs are mixed on different timescales. We will define two layer depths, one which evolves primarily in response to diurnal heating and a second which responds to surface forcing on timescales of days to weeks. In section 3 , we will describe the thermohaline structure of the upper ocean during and after the wind burst. In section 4, we will evaluate one-dimensional heat budgets for the two layers defined in section 2 . Our primary focus will be the role of the turbulent heat flux, and we will give a detailed discussion of the manner in which that flux is estimated and the errors inherent in that procedure in an appendix. We estimate that the turbulent heat flux, averaged over the duration of the wind burst, can be ascertained to within $10 \mathrm{~W} \mathrm{~m}^{-2}$ and also that the one-dimensional budget closes to within that tolerance. In section 5 , we evaluate the salt budget for the near-surface region. We will see that the evolution of SSS is not readily understood in terms of one-dimensional physics; it appears that lateral advection is important on both short and long timescales. Our results are summarized in section 6 .

\section{Mixing in the Near-Surface Region}

The wind stress record for the cruise (Figure 1a) featured three distinct periods of strong winds (Figure 1a, solid bands, top), each followed by a period of moderate wind (gray bands). We refer to these intervals collectively as "the" wind burst. The remainder of the occupation will be referred to as the "recovery" phase. During the wind burst, the near-surface region remained relatively well mixed, while cooling markedly in response to the surface heat flux (Figures $1 b$ and 1c). Salinity often decreased briefly in response to rainfall (Figures 1d and 1e) but exhibited no clear overall trend, while potential density increased due to surface cooling (Fig- ures $1 \mathrm{f}$ and $1 \mathrm{~g}$ ). During the recovery phase, stratification in the upper few tens of meters increased dramatically. This layer freshened markedly, despite light rainfall, while its temperature increased (and its potential density decreased) in association with surface warming.

The top of the main pycnocline was located roughly between depth $z=-60 \mathrm{~m}$ and $z=-100 \mathrm{~m}$; it deepened gradually during the wind burst, then ascended and spread upward during the recovery phase (Figure $1 \mathrm{~g})$. Strong mixing extended to the top of the pycnocline each night during the three phases of the wind burst (Figures 2a and 2b). Near-surface turbulent kinetic energy dissipation rates (Figure 2a) responded to both the wind stress and the diurnal cycle of the surface buoyancy flux (Figure 1f). However, there were several instances in which high dissipation rates were not directly associated with surface forcing. The subsurface turbulence regime appeared between $z=-50 \mathrm{~m}$ and $z=-90 \mathrm{~m}$ each night during periods of strong wind. Between January 4 and January 9, we observed persistent, intense turbulence at depth, despite weak surface forcing. In each of these cases, turbulence was driven indirectly by the surface forcing, as a regime of low gradient Richardson number was created by the shear at the base of the wind-driven surface current (SHM1).

On the basis of the buoyancy frequency $N^{2}$ (Figure $2 b$ ), we consider three distinct near-surface regions. These are bounded at the bottom by a pycnocline, which was characterized by values of $N^{2}$ near $10^{-3} \mathrm{~s}^{-2}$. The top of the pycnocline coincided roughly with the density $\sigma_{\theta}=22 \mathrm{~kg} \mathrm{~m}^{-3}$ isopycnal. In what follows, we refer to the region above the main pycnocline as the upper ocean layer (UOL). In the upper part of the UOL was a regime of weak stratification, with $N^{2}$ near $10^{-5} \mathrm{~s}^{-2}$ or less. In this regime, $N^{2}$ exhibited a clear diurnal variation which was associated with surface forcing in the same manner as turbulent kinetic energy dissipation rate $\epsilon$. On windy nights, $N^{2}$ often attained negative values of order $-10^{-6} \mathrm{~s}^{-2}$ over periods of several hours and depth ranges of several tens of meters. We refer to this near-surface region as the diurnal mixed layer (DML). We identify its base as the depth at which the density first exceeded its surface value by $0.01 \mathrm{~kg} \mathrm{~m}^{-3}$. (The latter is a standard definition for the depth of the layer which is mixed diurnally, e.g., Moum et al. [1989].)

Between the base of the DML and the top of the pycnocline was an intermediate region in which stratification was moderate $\left(N^{2} \sim 10^{-4} \mathrm{~s}^{-2}\right)$. This was the layer which remained in the aftermath of deep mixing on windy nights. Following Brainerd and Gregg [1995], we refer to it as the remnant layer (RL). Thus the UOL is composed of the DML plus the RL. These arbitrarily chosen depths correspond reasonably well to the boundaries one would define subjectively between the three stratification regimes discussed above (Figure $3 a$ ). The UOL deepened by $\sim 20 \mathrm{~m}$ over the course of the wind burst, except for shorter-period oscillations associated 


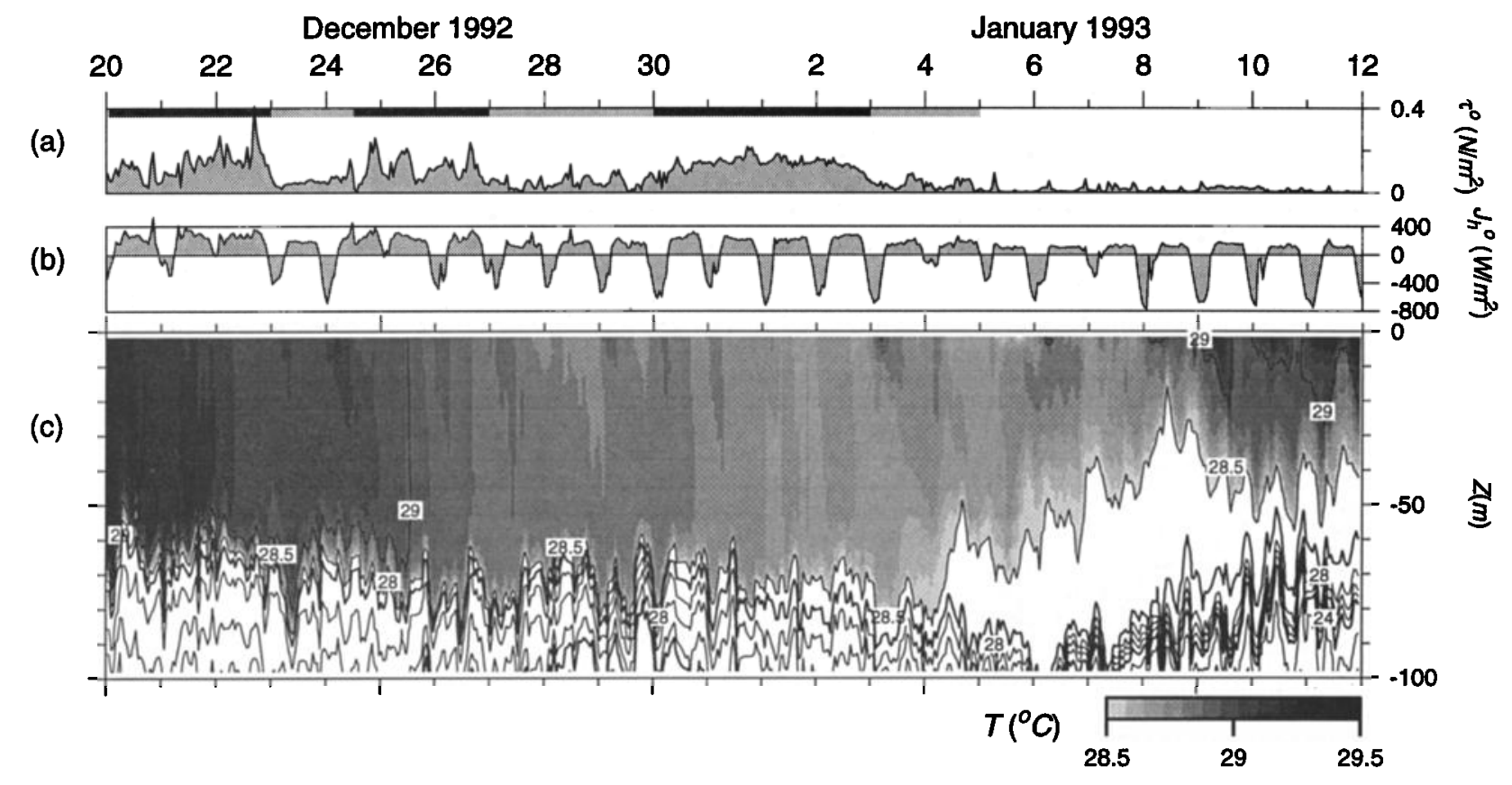

(d)

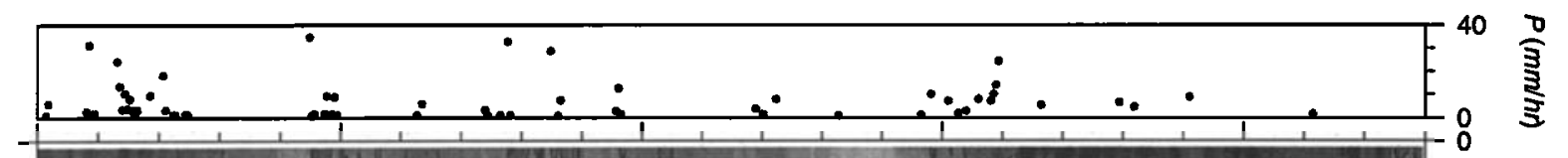

(e)

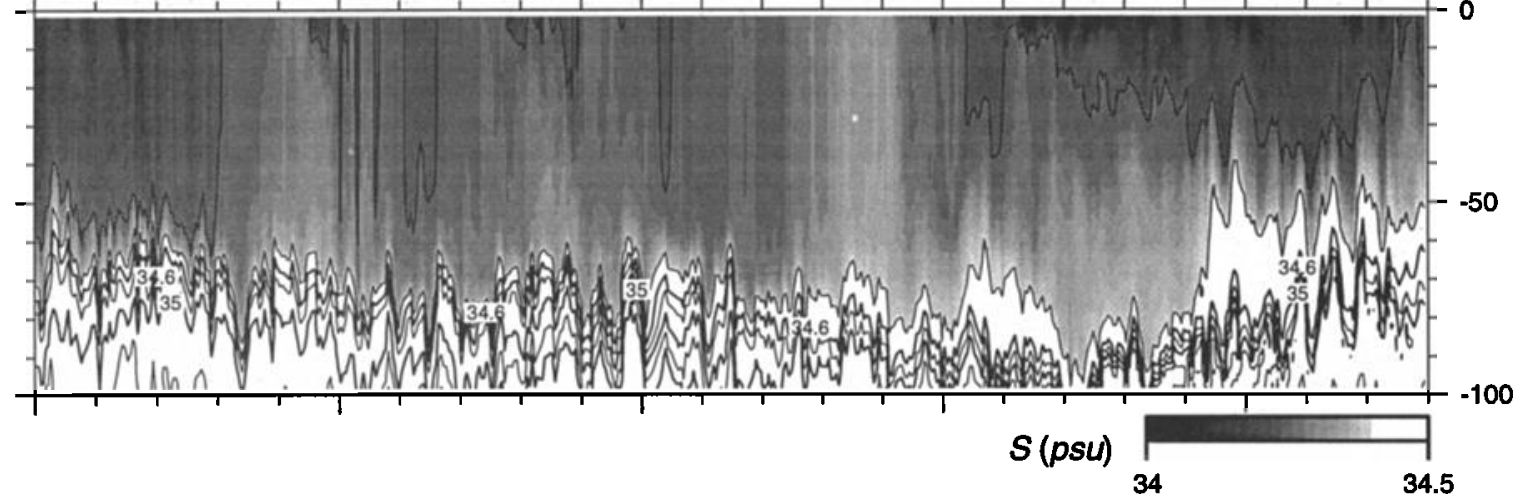

(f)

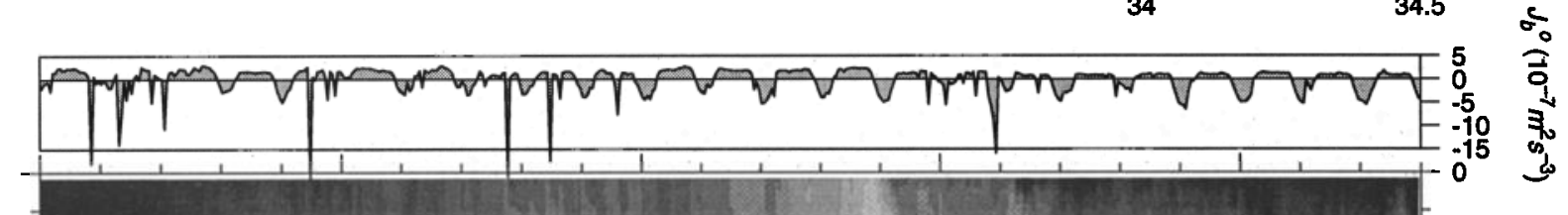

(g)

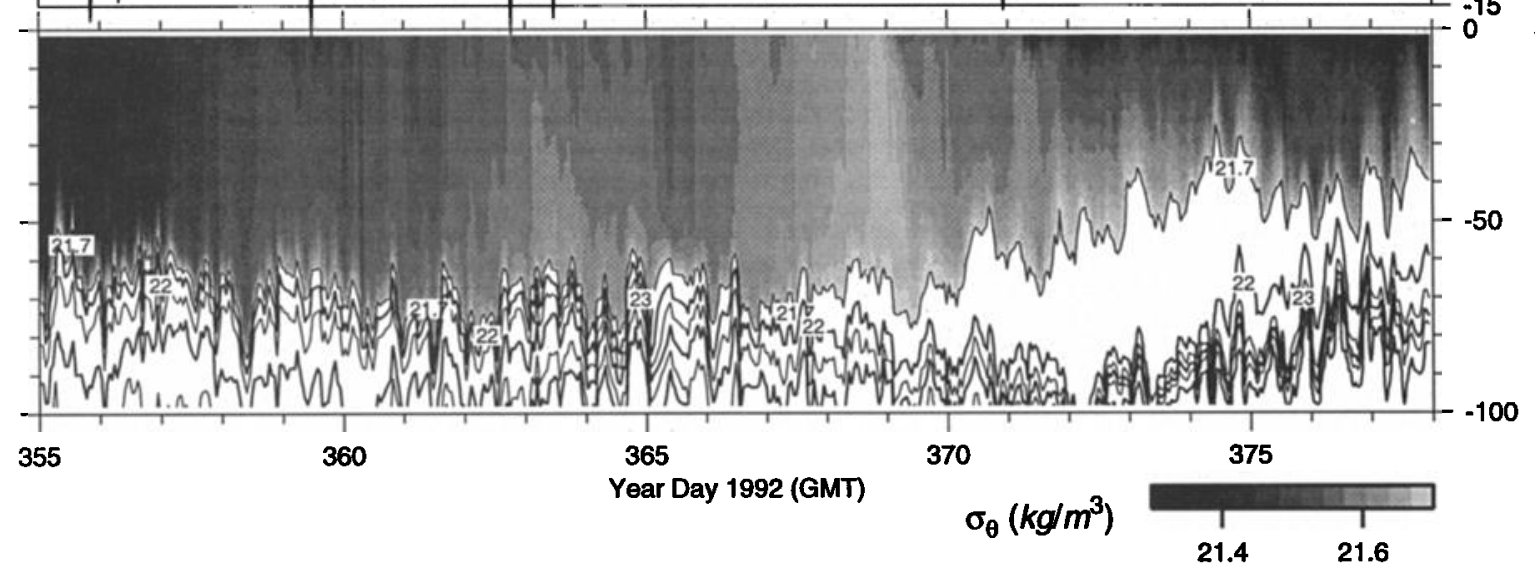

Figure 1. (a) Magnitude of the hourly averaged wind stress. Solid bands (top) indicate the three phases of the wind burst. (b) Net surface heat flux. (c) Temperature. (d) Hourly precipitation. (e) Salinity. (f) Net surface buoyancy flux. (g) Potential density. 
(a)

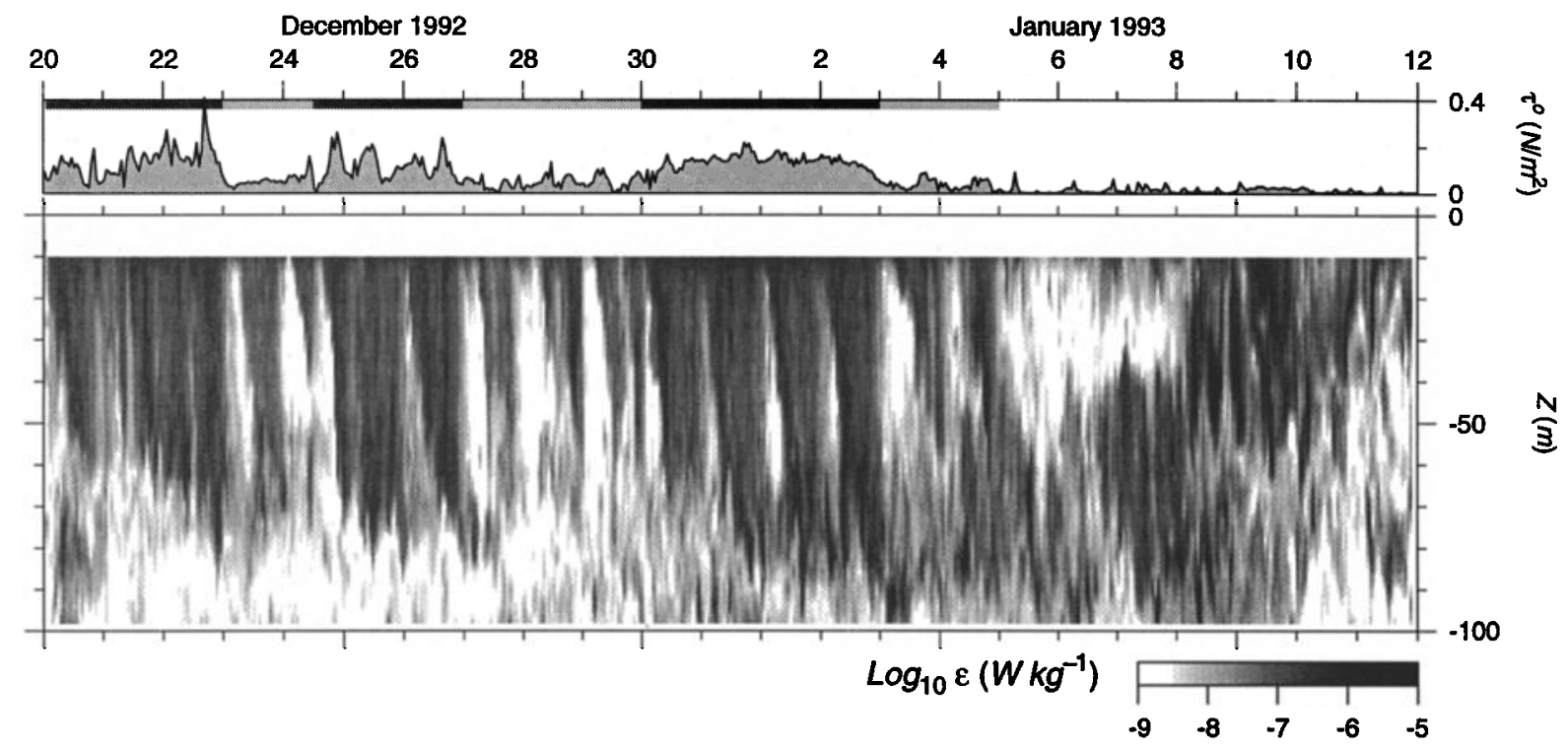

(b)

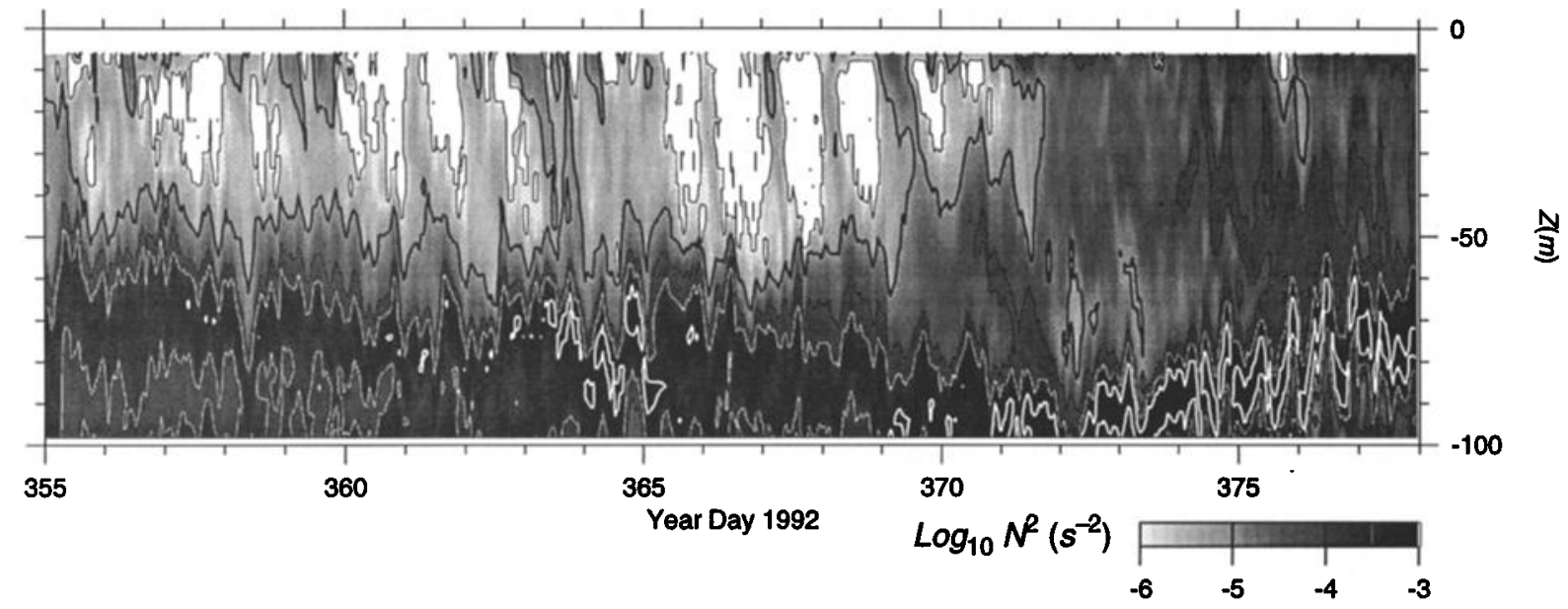

Figure 2. (a) Turbulent kinetic energy dissipation rate $\epsilon$. (b) Squared buoyancy frequency $N^{2}$. The vertical density derivative in $N^{2}$ has been calculated as an 8-m finite difference averaged over $4 \mathrm{~m}$. The white regions include regimes in which $N^{2}<0$. Black contours indicate the values $10^{-6}, 10^{-5}$, and $10^{-4}$. White contours indicate the values $10^{-3.5}$ and $10^{-3}$. Wind stress magnitude is also shown (top) (see Figure 1a).

with internal waves, then shallowed over several days after the wind burst. The DML responds to surface forcing on timescales of hours. In addition to wind forcing and the diurnal cycle of the surface buoyancy flux, the depth of the DML is strongly influenced by the intense buoyancy fluxes associated with rain events (compare with Figure 1d and downward spikes on Figure 1f).

There is considerable arbitrariness in the selection of a DML based on an objective criterion. Our real goal is to define a layer which is directly influenced by surface forcing from above and by turbulent entrainment from below. We can assess how well such a layer has been defined by comparing the vertically averaged temperature within the layer $T_{\mathrm{DML}}$, to SST (Figure $3 \mathrm{~b}$ ). (Our estimate of SST is obtained as a weighted average of profile temperatures between 0.5 and $4.0 \mathrm{~m}$ depth (see Figure 3). This estimate of SST is low for the days of greatest surface heating, when gradients in the upper few tens of centimeters were large ( $R$. Weller, personal communication, 1993), but these occurred primarily after the wind burst. The estimate may be somewhat high during the wind burst, as it does not include the cool skin.) SST exceeded $T_{\mathrm{DML}}$ only during periods of surface heating. The maximum temperature excess was $\sim 0.06^{\circ} \mathrm{C}$. For most of the wind burst, SST was smaller than $T_{\mathrm{DML}}$ by $0.01-0.03^{\circ} \mathrm{C}$ due to the intense surface cooling. This may indicate the presence of a superadiabatic surface layer [Anis and Moum, 1992]. The maximum excess of $T_{\mathrm{DML}}$ over SST, which occurred during rain squalls, was about $0.06^{\circ} \mathrm{C}$. The root-mean-square difference between SST and the average temperature in the DML was $0.018^{\circ} \mathrm{C}$.

\section{Thermohaline Structure}

Owing to heavy precipitation, salt stratification tends to be strong in the upper waters of the warm pool. Lukas and Lindstrom [1991] have observed that strong 

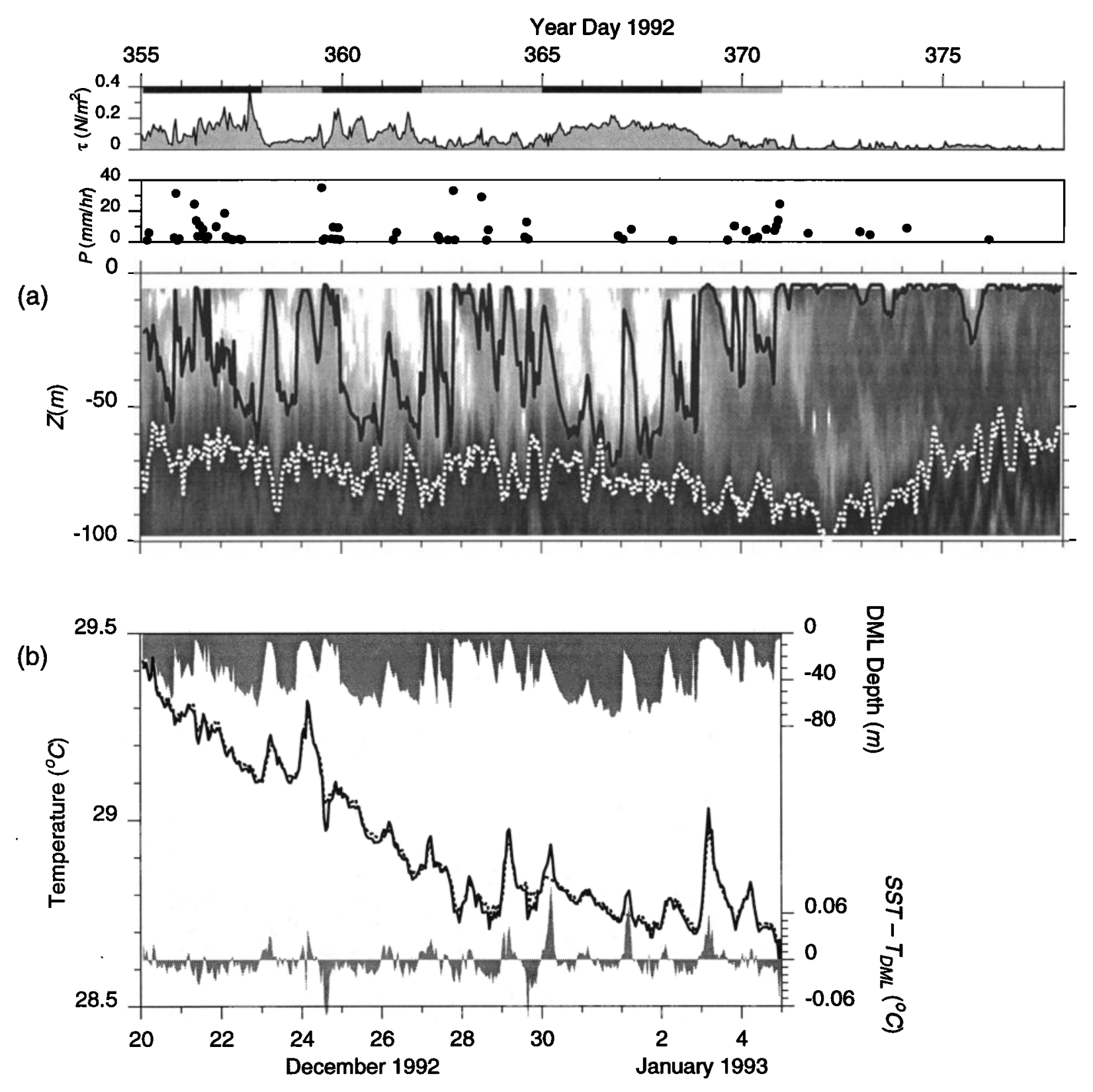

Mean, RMS average of $S S T-T_{D M L}=-.0035, .0179^{\circ} \mathrm{C}$

Figure 3. (a) Depth of the diurnal mixed layer (DML), defined as the depth at which the density first exceeds its surface value by $0.01 \mathrm{~kg} \mathrm{~m}^{-3}$ (solid curve), and depth of the upper ocean lyer (UOL), defined as the $1022 \mathrm{~kg} \mathrm{~m}^{-3}$ isopycnal (dotted curve). The background shading represents the squared buoyancy frequency (see Figure $2 \mathrm{~b}$ for scale). Wind stress magnitude $\tau$ and hourly rainfall $P$ (top) are also shown. (b) Approximate sea surface temperature (SST) (solid curve) and average DML temperature (dotted curve) during the wind burst. The top gray-shaded curve denotes the depth of the DML. The bottom gray-shaded curve indicates the difference between SST and DML temperature. SST was estimated from CHAMELEON measurements. (SST is estimated for each hour by taking the shallowest temperature value recorded for each profile within the hour (typically, $0.5 \mathrm{~m}-3.0 \mathrm{~m}$ ), then computing a weighted average using $1 /$ depth as the weight. The weighted average of the depths of the temperature measurements used is $1.5 \mathrm{~m}$.) 

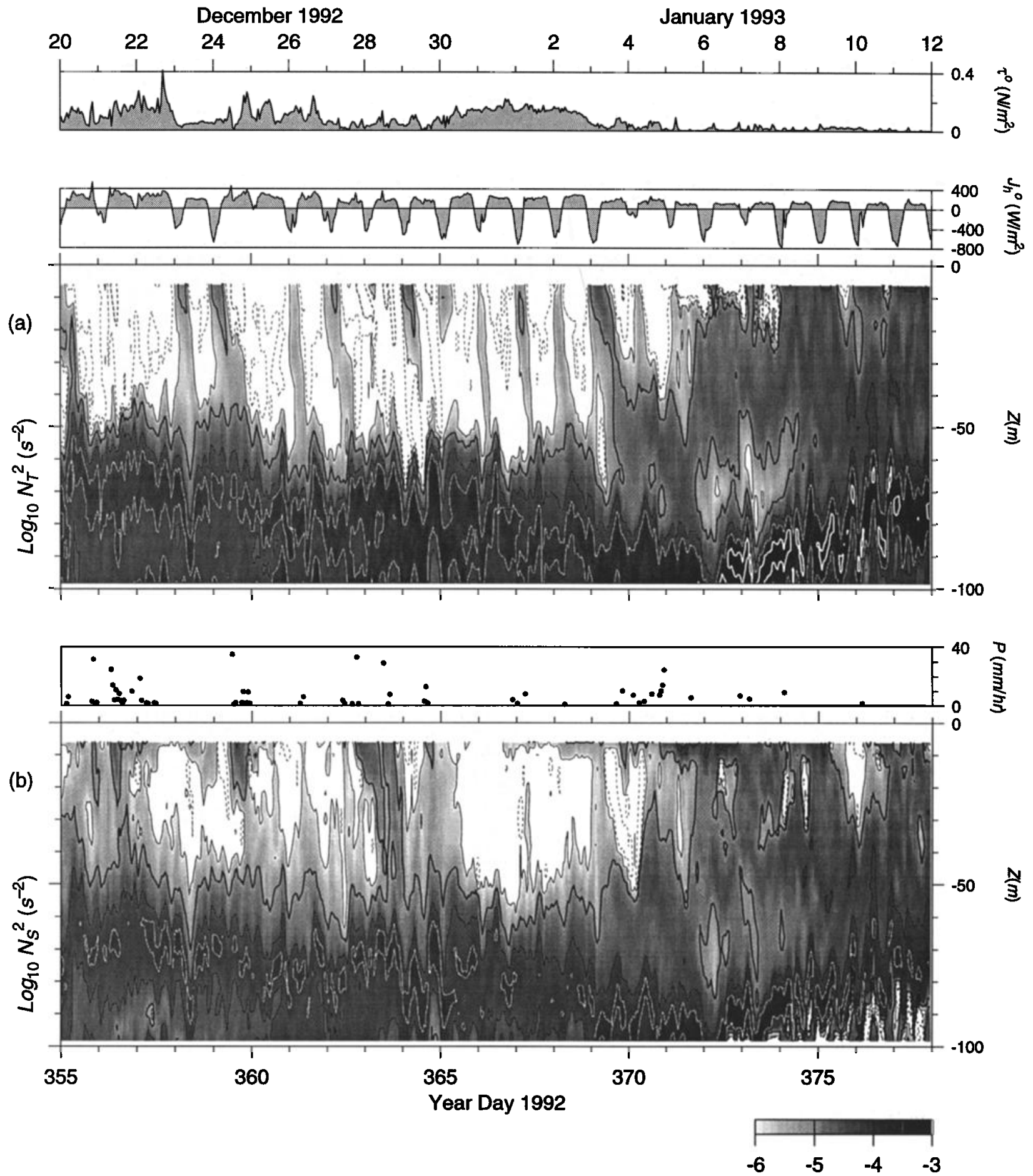

Figure 4. Components of the squared buoyancy frequency $N^{2}$ due to thermal and haline stratification. (a) $N_{T}^{2}=\alpha g \partial T / \partial z$ and (b) $N_{S}^{2}=-\beta g \partial S / \partial z$, where $\alpha$ and $\beta$ are the usual expansion coefficients for temperature and salinity. Solid contour values are the same as in Figure 2a. Dashed contours indicate unstable stratification; light gray and dark gray contours indicate the values $-10^{-6}$ and $-10^{-5}$, respectively.

salt stratification should tend to insulate the sea surface against mixing with the cooler water found in the thermocline. During our cruise, the component of the density stratification due to salinity was generally comparable in magnitude to that due to temperature (Figure 4). However, there was no distinct "barrier layer"
[Lukas and Lindstrom, 1991]; the thermocline and the halocline tended to be at the same depth.

Near the surface, thermal stratification was closely correlated with the surface heat flux (Figure 4a). During the wind burst, the diurnal heating cycle was apparent throughout the upper $50 \mathrm{~m}$, whereas these effects 
were confined to the upper few meters during the recovery period. Intense surface cooling during the wind burst frequently caused $N_{T}^{2}$ to be negative through most of the DML. The smallest (most negative) values were observed near the surface in conditions of strong surface cooling but light winds (e.g., day 359).

Salt stratification responded to surface forcing in much the same way as did thermal stratification (Figure $4 \mathrm{~b}$ ). Since the salt flux at the surface was predominantly positive, near-surface values of $N_{S}^{2}$ were generally positive as well. Stable salt stratification compensated, in general, for the unstable thermal stratification mentioned above (note the example on day 359), though there were brief periods in which $N^{2}$ became slightly negative near the surface.

Strong, stable salt stratification was ubiquitous within and above the thermocline, both during and after the wind burst, a consequence of the frequent rain squalls. An example is shown in Figure 5, which depicts cool, fresh water being mixed downward through the water column in the aftermath of a squall. In the mixing region, dissipation rates are of the order of $10^{-6} \mathrm{~W} \mathrm{~kg}^{-1}$, and overturns several meters in depth are visible in the density profiles. Below the mixing region, the dissipation rate drops by an order of magnitude or more. As the squall passed (Figure 5a), dissipation rates were $\sim 10^{-7} \mathrm{~W} \mathrm{~kg}^{-1}$ or greater throughout the upper $50 \mathrm{~m}$. Ninety minutes after the squall (Figure $5 \mathrm{~b}$ ), dissipation rates below $22 \mathrm{~m}$ had decreased dramatically. Stable salt stratification was the limiting factor on the penetration of surface-generated turbulence during this period [Smyth et al., 1996]. Note that the temperature beneath the squall-generated mixing region varied by about $0.01{ }^{\circ} \mathrm{C}$ between these three profiles. This is an example of the lateral patchiness of the near-surface hydrography which was observed throughout the WWB. (As an aside, we note that the rain temperature, estimated naively by extrapolating the T-S characteristics of the cool, fresh pools shown in Figure 5 to zero salinity, is close to freezing. In fact, the rain was only a few degrees cooler than the seawater (C. Fairall, personal communication, 1993). This illustrates the fact that most of the surface cooling was not due to rain input. Even in rainy conditions, evaporation was the dominant surface cooling mechanism. Similar results have been reported by Flament and Sawyer [1995], although their measurements were taken in calmer conditions, so that evaporative cooling was less intense.)

\section{Thermal Evolution}

As a result of the rain-influenced thermohaline structure discussed in the previous section, the vertical temperature gradient at the base of the DML was as likely to be negative as positive, and there was therefore relatively little net turbulent heat flux across that surface (Figure 6a), even though hourly flux values were sometimes as large as surface values. (Details of the turbulent heat flux calculations, including estimates of the associated uncertainties, are given in the appendix.) An example of large negative temperature gradient is the set of postsquall profiles shown in Figure 5 . In each case, the base of the DML, as identified by the $\Delta \sigma=0.01 \mathrm{~kg} \mathrm{~m}^{-3}$ criterion, lies within the strongly mixing region near the surface. The heat flux through the layer was approximately $+200 \mathrm{~W} \mathrm{~m}^{-2}$ for the first and second profiles shown, $+60 \mathrm{~W} \mathrm{~m}^{-2}$ for the third.

Over the duration of the wind burst, the time-averaged turbulent heat flux across the base of the DML was $-11 \mathrm{~W} \mathrm{~m}^{-2}$, while the root-mean-square (RMS) average of the hourly values was $79 \mathrm{~W} \mathrm{~m}^{-2}$. Strong upward fluxes occurred mainly during rainy periods, as cool rainwater was mixed downward through the water column (e.g., days 356 and 359). In contrast, heat fluxes near the base of the UOL were always directed downward (Figure $6 \mathrm{~b}$ ), with cruise mean equal to $-18 \mathrm{~W} \mathrm{~m}^{-2}$. (Because wind burst effects persisted to the end of the cruise at this depth in the form of enhanced shear at the top of the pycnocline, the cruise mean is representative of WWB conditions.) The RMS average flux at the base of the UOL was $50 \mathrm{~W} \mathrm{~m}^{-2}$. For comparison, the mean and RMS average of the surface heat flux were +25 and $256 \mathrm{~W} \mathrm{~m}^{-2}$, respectively.

The one-dimensional heat budget to be employed here is defined using the heat equation, which we integrate in the vertical and write as

$$
\rho c_{p} \int_{-h}^{0} \frac{\partial T}{\partial t} d z=-J_{h}+\left.F_{R}\right|_{-h}+\left.F_{T}^{h}\right|_{-h}+R
$$

where $\rho c_{p}$ is the volumetric heat capacity, to which we assign the constant value $4 \times 10^{6} \mathrm{~J} \mathrm{~K}^{-1} \mathrm{~m}^{-3} ; h(t)$ is an arbitrary, time-dependent depth; $J_{h}$ is the total surface heat flux; and $F_{R}$ represents the heat flux due to solar radiation penetrating to depth $z=-h$. This flux was estimated from radiation profiles made at the time of our measurements in the COARE region by Siegel et al. [1995]. $F_{T}^{h}$ is the turbulent flux. Finally, $R$ is the residual, representing the combined effect of terms not contained in the one-dimensional budget and inaccuracies in the values of the terms we have estimated. Each term on the right-hand side of (1), if positive, represents a contribution to the heating of the layer between the surface and depth $h$. Note that the left-hand side of (1) cannot be nonzero merely as a consequence of changes in $h$, as would be the case, for example, if we wrote (1) as an evolution equation for the heat content of the layer, $\rho c_{p} \int_{-h}^{0} T d z$. In (1), the left-hand side responds only to actual changes of local temperature occurring within the layer.

In our first analysis of the heat budget, $h(t)$ will represent the base of the DML. Since the average temperature of the DML differs very little from SST (Figure $3 \mathrm{~b}$ ), we assume that this layer is directly forced by the surface. This analysis is meant to quantify the subsurface processes which modulate SST evolution. Later in this section, we will display results for a second calcula- 


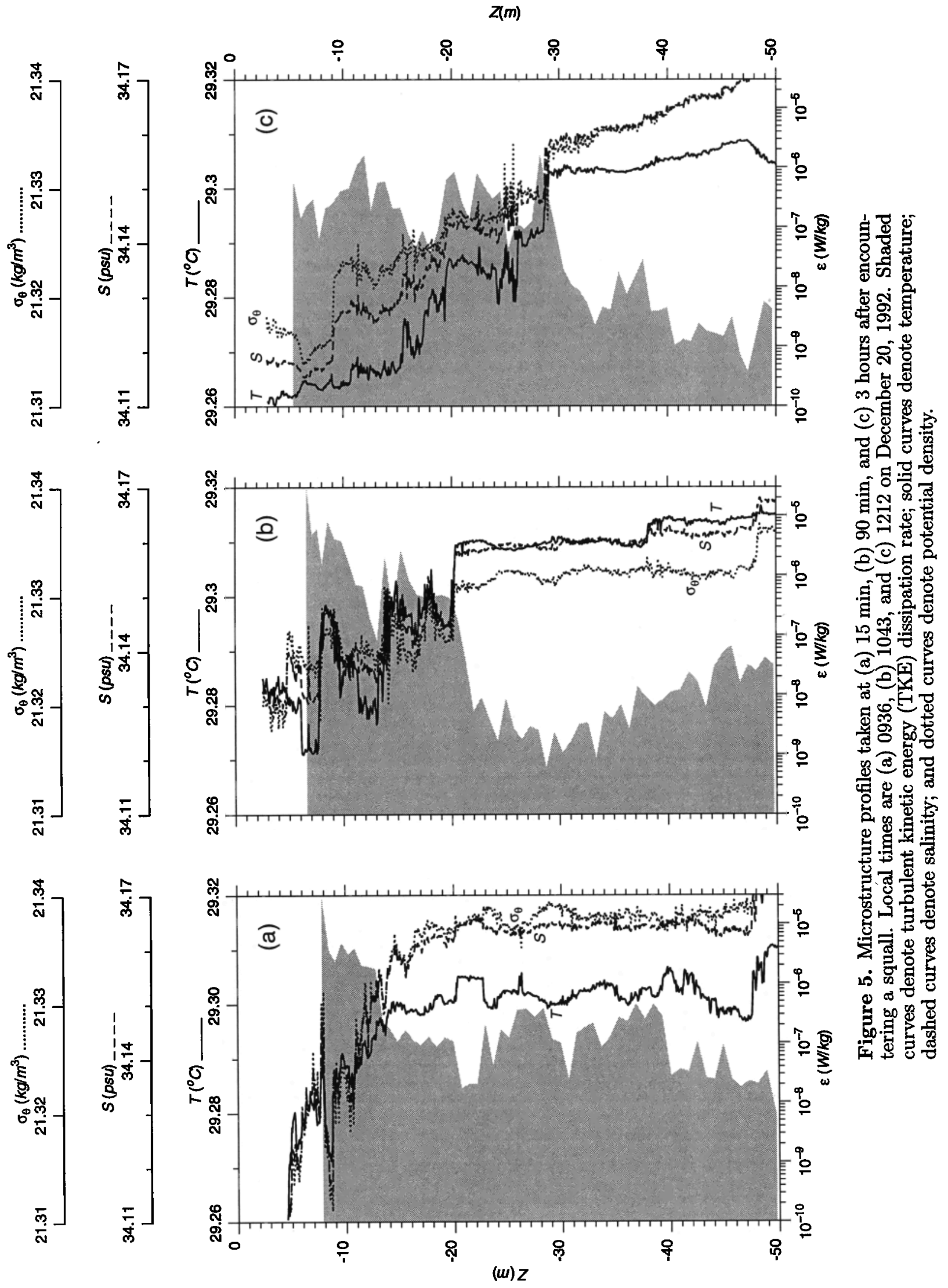



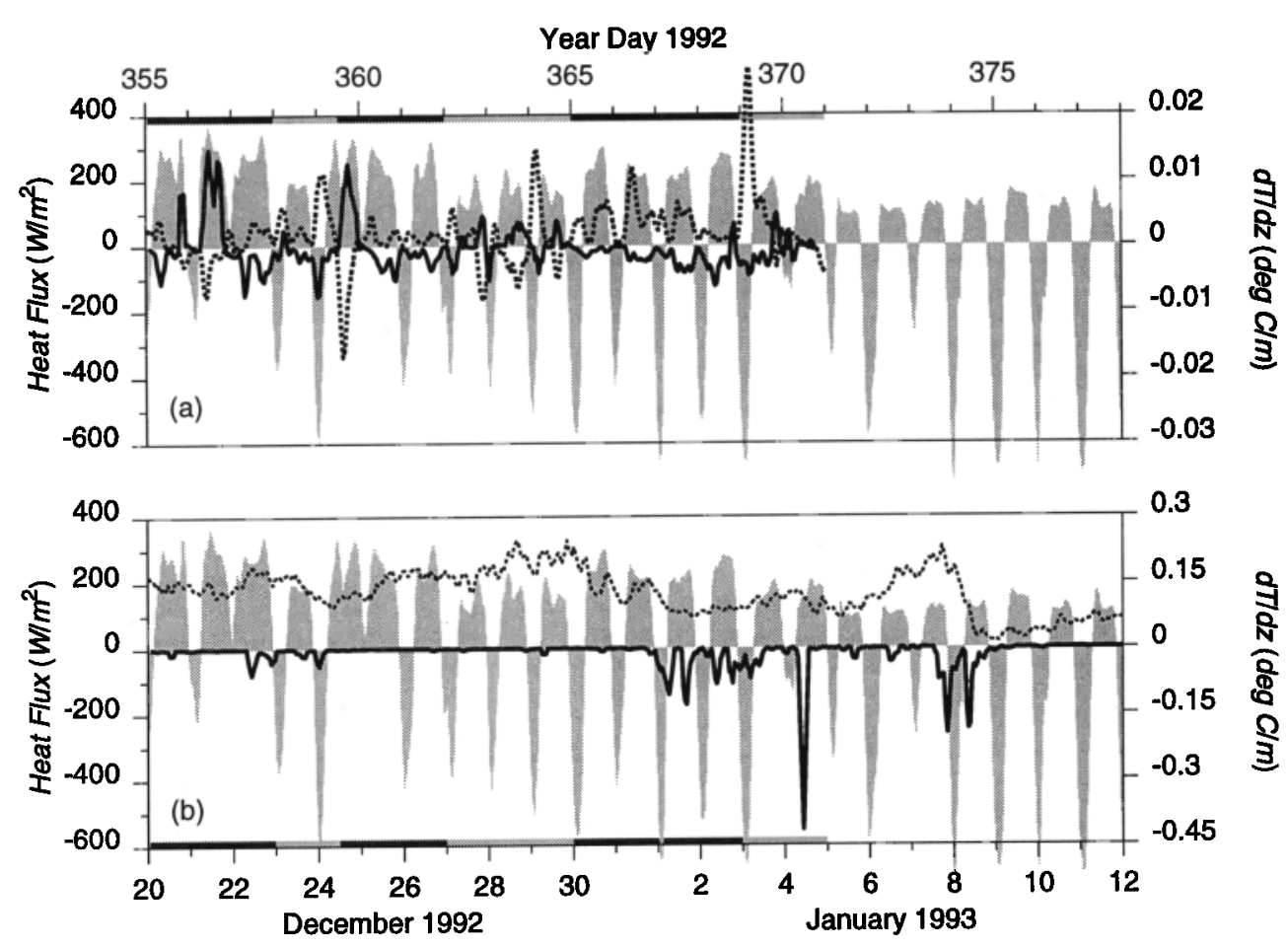

Figure 6. (a) Vertical turbulent heat flux (solid curve) and vertical derivative (over $8 \mathrm{~m}$ ) of temperature (dotted curve) at the base of the DML. The gray-shaded curve indicates the net surface heat flux. Positive values indicate upward flux. The methods used to compute the subsurface turbulent fluxes are discussed in the appendix. No turbulent heat fluxes were calculated after the end of the wind burst, since the DML was very shallow during most of the subsequent recovery period, resulting in invalid $\epsilon$ data. Dark and light bands (top) indicate the phases of the wind burst, as in Figure 2a. (b) Same as Figure 6a, but for the base of the UOL.

tion, in which $h(t)$ is situated at the base of the UOL. In each instance, we consider the cumulative heat budget, obtained by integrating (1) from day 355 (the beginning of our station; see Figures 7 and 8), in addition to fluxes averaged over specific intervals of interest (Figure 9). We will make reference to phases 1,2 , and 3 of the wind burst; these intervals correspond to the three periods of strong wind identified in Figure 2a. They are defined as $355.0<t<358.0,359.5<t<362.0$, and $365.0<t<369.0$, with $t$ given as 1992 year day (see SHM1, Figure 2a, and the accompanying discussion).

The net heating of the mixed layer (Figure 7a, solid curve) was generally negative during the wind burst, corresponding to a decrease in SST and DML temperature of about $0.8^{\circ} \mathrm{C}$ (Figure $3 \mathrm{~b}$ ). The fact that the net heating and the cumulative surface flux (Figure 7a, dashed curve) do not coincide is due to the action of subsurface heat fluxes (Figure $7 \mathrm{~b}$ ). In phase 1, surface cooling was intense due to heavy rainfall. Cooling of the DML was reduced, however, by the entrainment of warmer water from below across the base of the layer. This entrainment process occurred mainly during the intense squall activity of December 21. Following this came a 2-day period in which the DML was cooled from below, so that by December 24, the cumulative effect of the turbulent heat flux was close to neutral. During phase 2, the DML was again cooled from above, but in this case, surface cooling was less intense than that which occurred in phase 1 . Again, turbulence acted to mix relatively warm water from the $R L$ into the DML. This mixing occurred primarily during a single event on December 24, when the DML was shallow due to rain. During the remainder of phase 2 (December 25 and 26), the turbulent flux exerted a mild cooling influence. On December 25, a rapid cooling was observed, which cannot be accounted for by mechanisms included in our one-dimensional heat budget. Lateral surveys of the upper ocean made at the same time as our measurements indicate that this cooling event was caused by the passage of an oceanic cold front (E. Antonissen et al., manuscript in preparation, 1996).

In the interval between phases 2 and 3 , periods of heavy rain brought the base of the DML close to the surface, so that in intervening sunny periods, a large fraction of the incident sunlight penetrated beyond the base of the DML (indicated by the negative slope of the dashed curve on Figure 7b). Downward mixing of rainwater is again evident from the sign of the turbulent flux (Figure 6a). The surface heat flux exerted no influence, on average, and the net result was a very slight cooling of the DML during this interim period. In phase 3 of the wind burst, the net surface flux was near zero, 


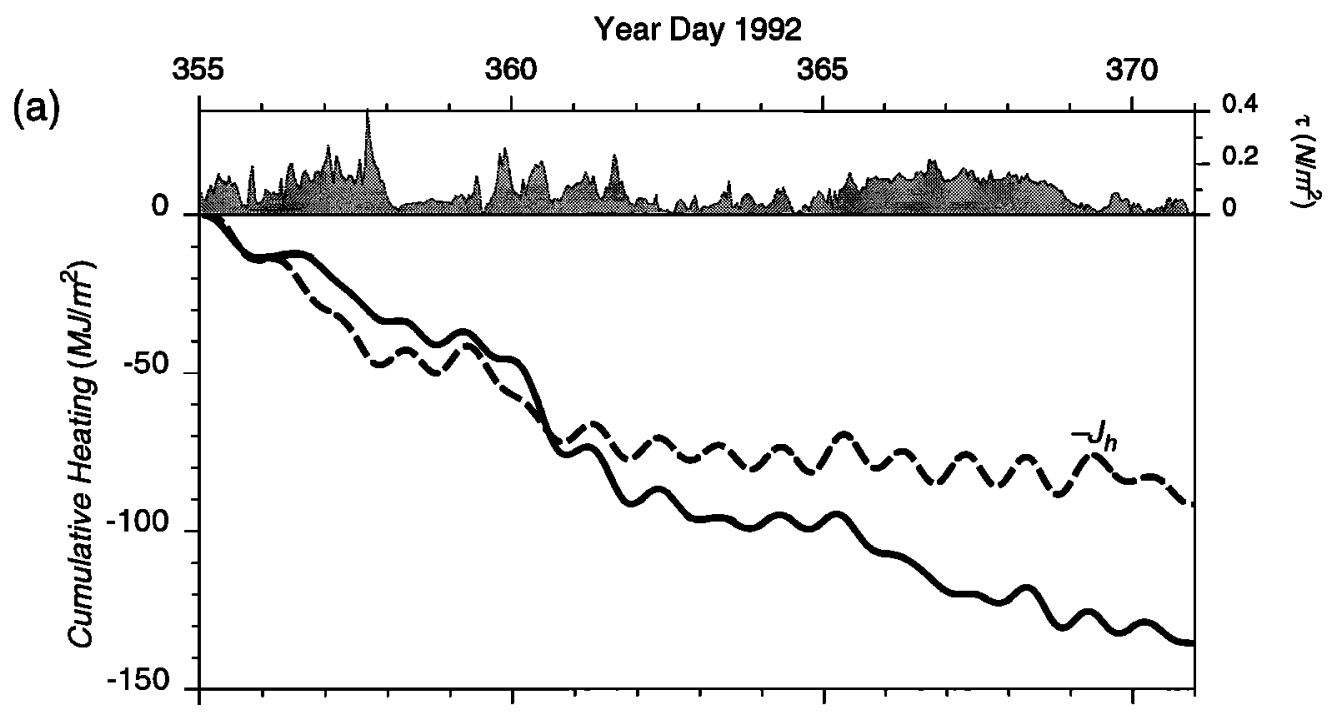

(b)

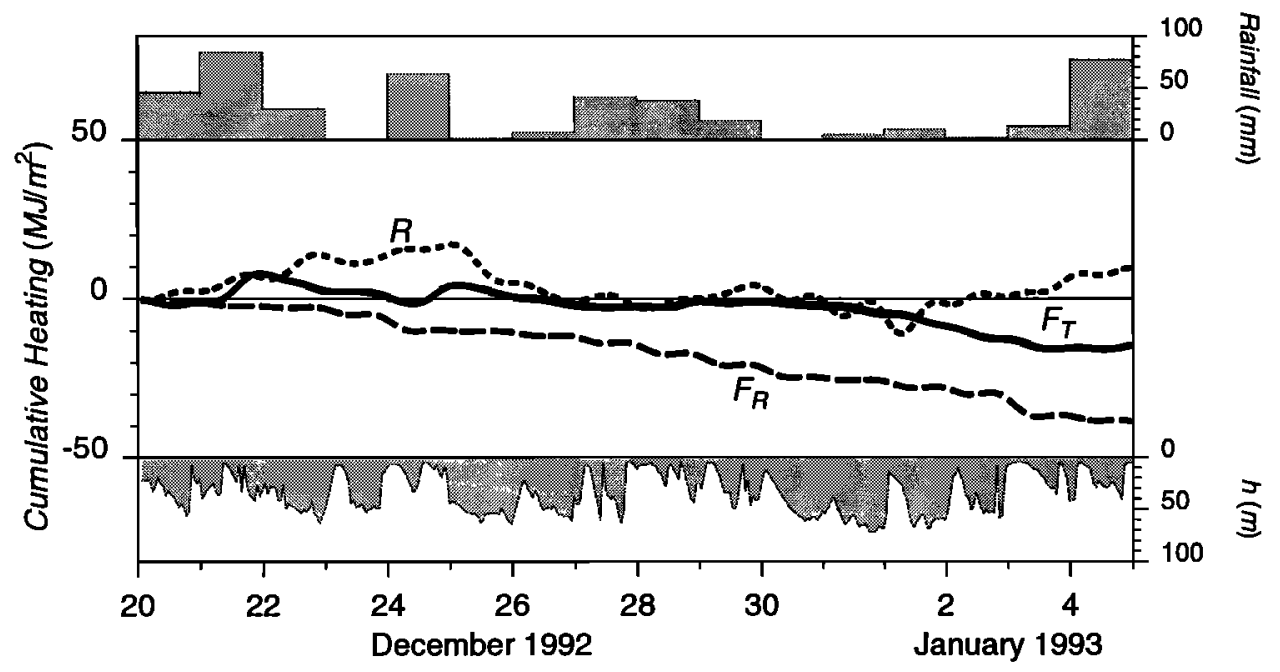

Figure 7. Accumulated (i.e., time integrated) heat fluxes into the DML. (a) Net heating rate of the DML (solid curve) and surface heat flux (dashed curve). (b) Turbulent heat flux (solid curve), heat flux due to penetrating radiation (dashed curve), and residual (additional heat flux needed to account for observed heating of the mixed layer) (dotted curve). All quantities in (1) are computed hourly, smoothed with a 1.25 cpd low-pass filter, then integrated in time from the beginning of the station. Shaded curves represent hourly wind stress magnitude, daily rainfall, and hourly average temperature and layer depth, as indicated on axis labels.

but significant heat was lost to penetrative radiation. In addition and in contrast to phases 1 and 2, the turbulent flux was substantial and was directed downward. Owing to the strong wind and the relative absence of rain, the DML became relatively deep during this interval, so that the turbulent heat flux was dominated by entrainment of cool water from the thermocline. This result emphasizes the sensitivity of the turbulent flux at the DML base to precipitation. During phase 1, precipitation was heavy and the average turbulent flux was $+10 \mathrm{~W} \mathrm{~m}^{-2}$ (Figure 9c). During phase 3, there was very little precipitation and the average turbulent flux was $-35 \mathrm{~W} \mathrm{~m}^{-2}$ (Figure $9 \mathrm{~g}$ ). The overall result of the wind burst was a cooling of the DML of $\sim 0.8^{\circ} \mathrm{C}$, on av- erage, and a corresponding heat loss of $\sim 130 \mathrm{MJ} \mathrm{m}^{-2}$ (or $98 \mathrm{~W} \mathrm{~m}^{-2}$ on average).

Like the DML, the UOL cooled substantially during the wind burst (Figure 8a). Additional cooling occurred early in the recovery period but was countered by rapid warming on January 9 and 10 . The subsurface radiative flux was weak at this depth. The turbulent flux exerted a cooling effect during and after phase 3 of the wind burst, as wind-driven currents developed intense shear near the base of the UOL. However, the effect of the turbulent flux is insufficient to account for the observed cooling. The results suggest that most of the cooling of the UOL occurred during the front passage of December $25-26$. The additional cooling event of January $6-9$ 

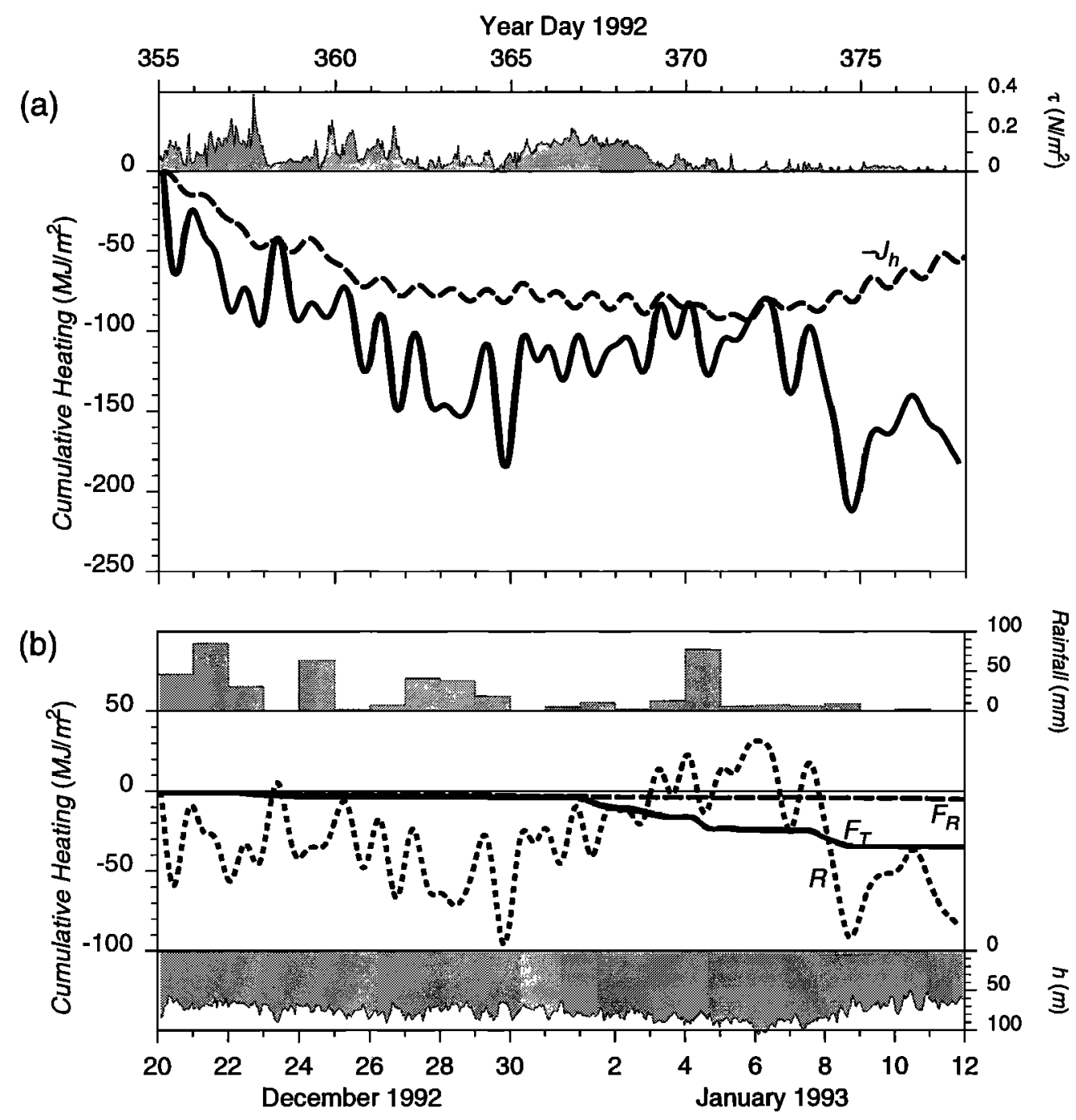

Figure 8. Same as Figure 7, but for accumulated heat fluxes into the UOL.

and the subsequent warming also appear to be due to lateral advection (E. Antonissen et al., manuscript in preparation, 1996). Both of these advective events are associated with equatorward currents which arose as a secondary effect of the wind forcing (SHM1).

We complete our discussion of thermal evolution with a look at the restratification which occurred in the upper $\sim 70 \mathrm{~m}$ during the recovery period (Figure $1 \mathrm{~g}$ ). A similar (though possibly weaker) restratification event was observed after the wind burst of October-November 1992 [Wijesekera and Gregg, 1996]. In each case, the wind burst was followed by a period of intense, sheardriven turbulence at the top of the pycnocline (SHM1), and it is tempting to suggest that this mixing caused the restratification by entraining dense fluid from the pycnocline. (In Figure 1g, note the correspondence between the spreading of isopycnals upward from the top of the pycnocline and the regime of strong subsurface mixing visible in Figure 2a.) The restratification process involved cooling of the fluid above the pycnocline which, if the hypothesis given above is correct, is due to the turbulent heat flux downward into the pycnocline. Analysis of the heat budget therefore allows us to assess the magnitude of the turbulent flux in comparison to that which is needed to explain the observed restratification. Somewhat arbitrarily, we define the restratification to have occurred during the interval January 4-9, inclusive (Figure 1g), and compute the average values of the terms in (1) for that period (Figure 10).

During the restratification period, the water column above the $22 \mathrm{~kg} \mathrm{~m}^{-3}$ isopycnal cooled at an average rate of $64 \mathrm{~W} \mathrm{~m}^{-2}$. The surface heat flux was directed into the ocean and warmed the surface at an average rate of $6 \mathrm{~W} \mathrm{~m}^{-2}$, while $1 \mathrm{~W} \mathrm{~m}^{-2}$ of this incoming heat was lost to penetrative radiation. We are left with a cooling of $69 \mathrm{~W} \mathrm{~m}^{-2}$ associated with the restratification process. The turbulent flux, however, accounts for only $34 \mathrm{~W} \mathrm{~m}^{-2}$ of this; the remaining $35 \mathrm{~W} \mathrm{~m}^{-2}$ appears as a residual. These numerical values are sensitive to the choices of time interval and depth range. For comparison, we have also calculated the budget for the layer above the $21.7 \mathrm{~kg} \mathrm{~m}^{-3}$ isopycnal (see Figure $1 \mathrm{~g}$ ). 

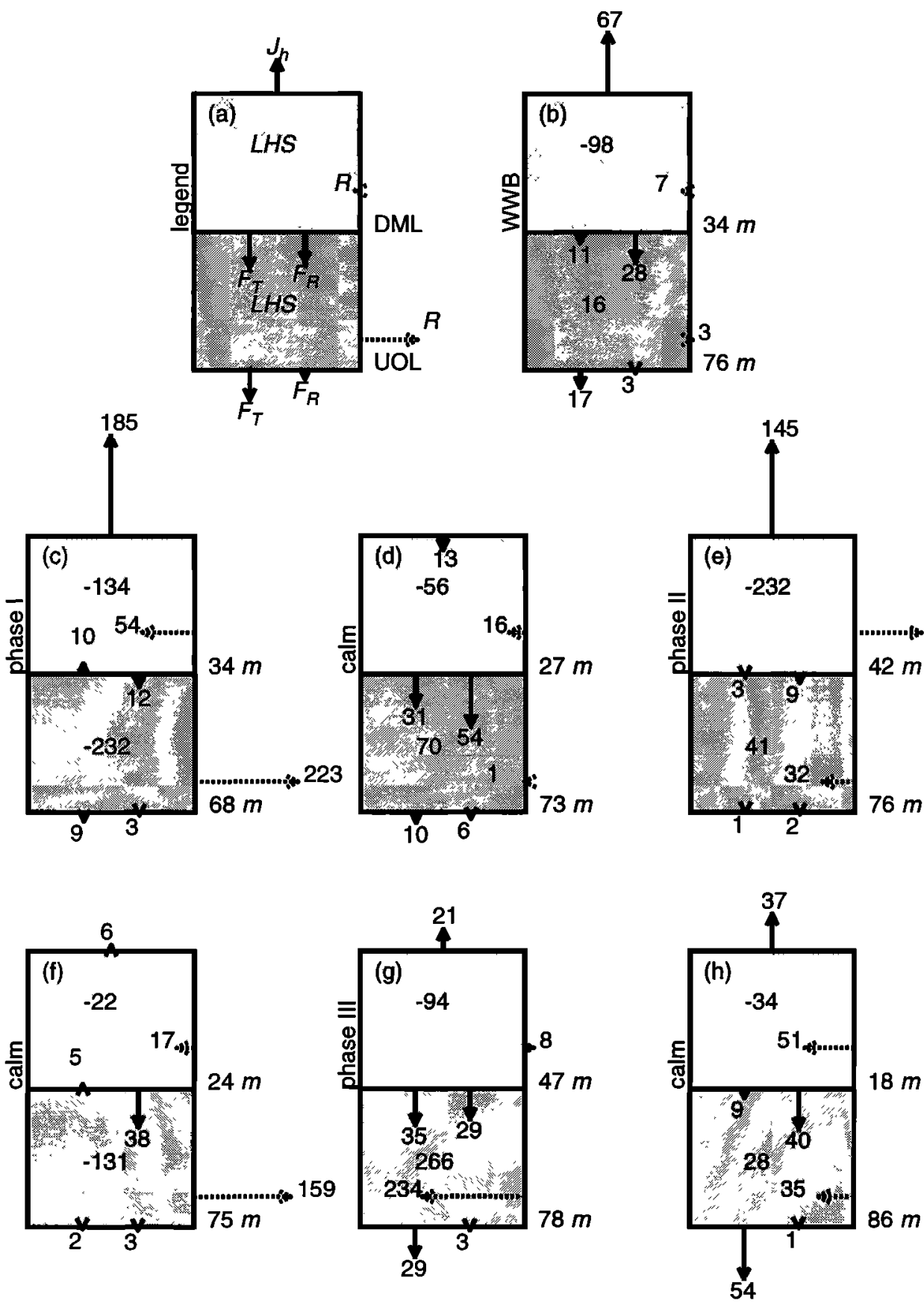

Figure 9. Box diagrams showing the average sizes of the terms in the heat budget during various phases of the wind burst. The top half of each represents the DML, and the quantities listed are the terms in equation (1). The bottom half of each represents the remnant layer (RL), for which the heat budget is a slight modification of (1): $\rho c_{p} \int_{h_{2}}^{h_{1}} \frac{\partial T}{\partial t} d z=-\left.F_{R}\right|_{h_{1}}+\left.F_{R}\right|_{h_{2}}+-\left.F_{T}^{h}\right|_{h_{1}}+$ $\left.F_{T}^{h}\right|_{h_{2}}+R$, in which $h_{1}$ and $h_{2}$ indicate the bases of the DML and the UOL, respectively. All fluxes are in units of watts per square meter. (a) Legend for left-hand side (LHS). (b) Entire westerly wind burst (WWB), days 355-371 inclusive. (c) Phase 1, days $t=355,358$. (d) Calm period; $t=358.0,359.5$ ). (e) Phase 2, $t=359.5,362.0$. (f) Calm period, $t=362,365$. (g) Phase $3, t=365,369$. (h) Calm period, $t=369,371$. 

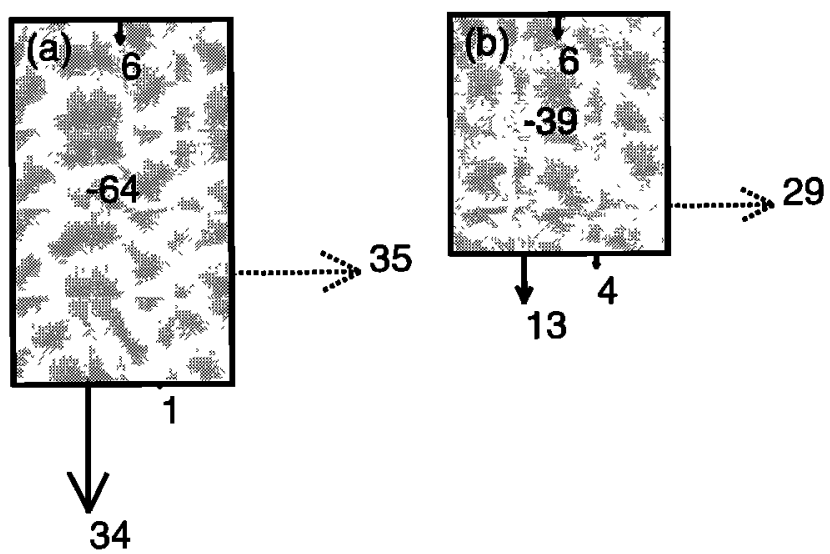

Figure 10. Box diagrams showing the heat budget for the restratification period, defined as $t=369.0,374.0$. Budgets are evaluated from the surface down to (a) the $22 \mathrm{~kg} \mathrm{~m}^{-3}$ isopycnal and (b) the $21.7 \mathrm{~kg} \mathrm{~m}^{-3}$ isopycnal. See Figure 9a for legend.

The results are similar; mixing accounts for $31 \%$ of the cooling associated with restratification. If all quantities have been estimated accurately, the residual represents vertical and/or horizontal advection, neither of which can be estimated reliably from our data.

\section{Salinity Evolution}

The one-dimensional salt budget is defined analogously with (1), namely:

$$
\int_{-h}^{0} \frac{\partial S}{\partial t} d z=-S_{o}(P-E)+\left.F_{T}^{s}\right|_{-h}+R .
$$

$S_{o}(P-E)$ is the equivalent surface salt flux. $S_{o}$ is the surface salinity; $P$ and $E$ are precipitation and evaporation rates, respectively. $F_{T}^{s}$ is the turbulent salt flux. $R$ is the residual and represents advective effects, as well as errors in our estimates of the other terms in the budget. To estimate the turbulent salt flux, we employ the usual flux gradient formulation and assume that the turbulent diffusivity for salt is equal to that for density, so that

$$
F_{T}^{s}=-K_{\rho} \frac{\partial S}{\partial z}
$$

The cumulative salt budget for the DML during the wind burst (Figure 11a) reveals that the surface and turbulent salt fluxes, averaged over the duration of the wind burst, as described above, are nearly equal. In fact, each period of heavy rain is followed by a period of 2-5 days (depending on the magnitude of the rainfall) in which evaporation and upward turbulent flux combine to bring the cumulative fluxes close to equality. Following each such period, the turbulent flux decreases nearly to 0 (indicating a small vertical salinity gradient) until the next period of heavy rainfall. (During those few times that the DML was too shallow to permit the use of the dissipation method for estimating $K_{\rho}$, we have assumed that the turbulent flux at the DML base is equal to the surface flux. This would appear to be a valid assumption, since that equality holds so well, even when the DML is deep.)

Despite heavy rainfall, there was a net input of salt to the DML during the wind burst which was driven primarily by factors other than the vertical fluxes whose values we have estimated here. Salinity changes on short timescales were generally uncorrelated with rainfall and suggest the passage of freshwater pools left by previous rain events. Integrated over the period of the wind burst, the turbulent salt flux across the base of the DML was equivalent to a net freshwater flux of $240 \mathrm{~mm}$, which very nearly balances the excess of precipitation over evaporation during this period. Examining the cumulative salt budget for the UOL (Figure $11 b$ ), we note that the turbulent flux was weak in comparison to the other terms and it appears that most of the freshwater input at the surface remained within the UOL. The total flux over the cruise was equivalent to a net freshwater input of $90 \mathrm{~mm}$ or an average input of $3.9 \mathrm{~mm}$ day $^{-1}$. This is close to Donguy's [1987] estimate of the annual mean excess of precipitation over evaporation, i.e., $150 \mathrm{~cm} \mathrm{yr}^{-1}\left(=4.1 \mathrm{~mm} \mathrm{day}^{-1}\right)$. Despite the weak vertical flux, there was a strong tendency for the UOL to become saltier with time, a tendency which we again ascribe to horizontal advection. During the final week of the station, the salinity of the UOL increased in a manner similar to the temperature. This salinity increase was associated with the restratification event discussed in the previous section. Only a small part of the salinity increase can be explained by turbulent mixing.

An overall picture suggested by these results is one in which fresh water input from rainfall is mixed efficiently through the DML and therefore has minimal effect on the salinity of that layer, but substantial changes in the latter are driven by horizontal advection. Most of the fresh water from precipitation remains within the UOL (that is, not much is mixed into the thermocline). Advection occurs both on short timescales associated with the passage of freshwater pools and on the longer timescale of the wind burst itself.

\section{Discussion}

The wind burst which occurred during the COARE IOP generated a mean heat flux of $67 \mathrm{~W} \mathrm{~m}^{-2}$ out of the ocean surface. During the same period, SST dropped by $0.8^{\circ} \mathrm{C}$. We have estimated the subsurface fluxes which modulate the response of SST to surface forcing and have seen that vertical fluxes account well, on average, for the observed net cooling. The radiative flux through the base of the DML represented an additional $28 \mathrm{~W} \mathrm{~m}^{-2}$ of cooling.

The turbulent heat flux at the base of the DML was large instantaneously $\left(O\left(100 \mathrm{~W} \mathrm{~m}^{-2}\right)\right)$, but it was di- 

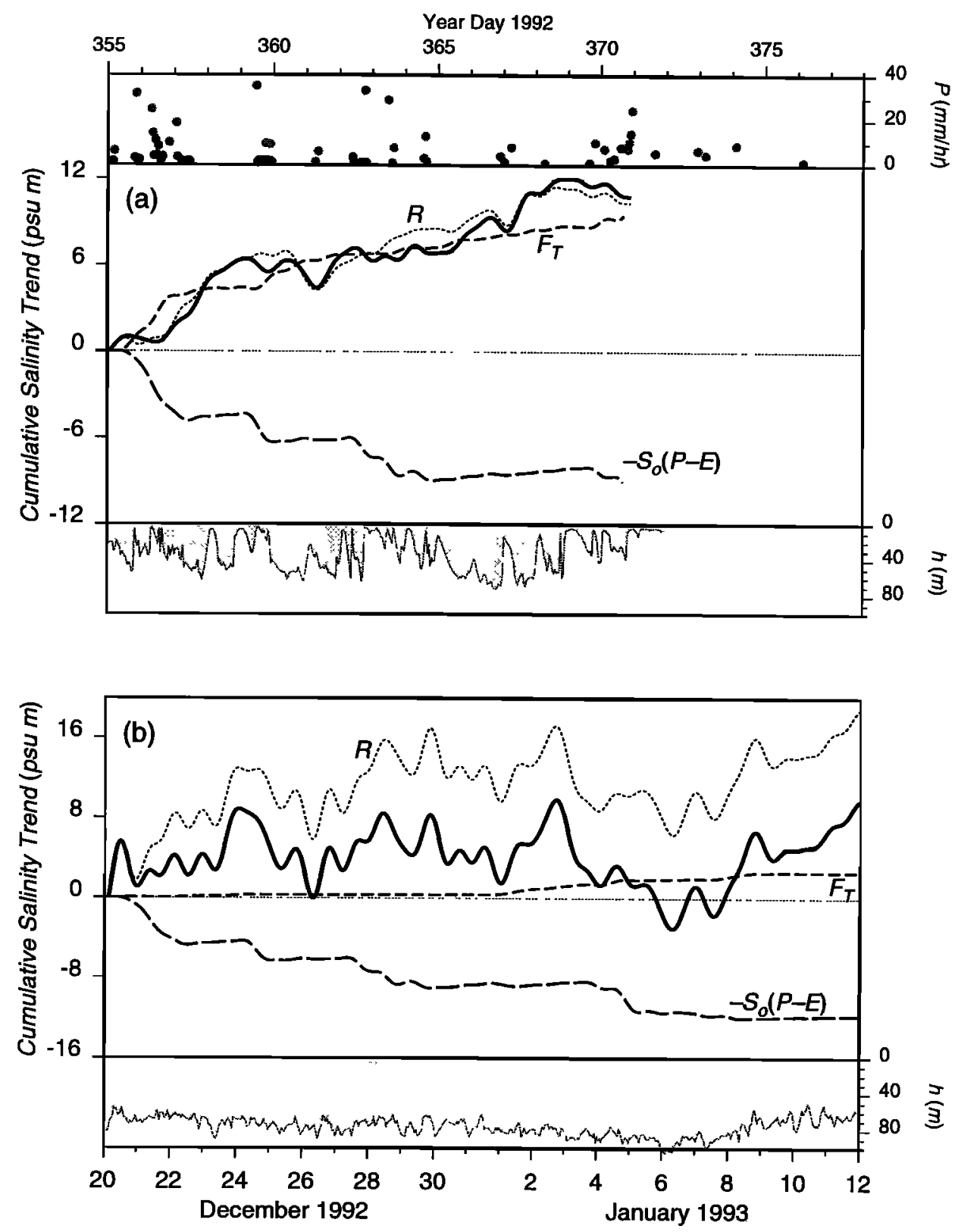

Figure 11. Accumulated salt fluxes into the (a) DML and (b) UOL. Solid curves are integrated salinity trend; long-dashed curves are equivalent surface flux; short-dashed curves are turbulent flux; and dotted curves are residual (additional salt flux needed to account for observed salinity changes in the layer). Figure 11a (top) shows hourly rainfall. Figures 11a and 11b (bottom) show the corresponding layer depth.

rected upward as often as downward due to instances of intense surface cooling and shallow DML associated with squalls and was therefore small, on average. The importance of precipitation in determining the role of turbulent entrainment in the near-surface heat budget is well illustrated by the difference between phases 1 and 2 of the WWB (compare Figures $9 \mathrm{c}$ and $9 \mathrm{~g}$ ). Each event involved strong winds, but phase 1 also involved heavy rainfall while phase 3 did not. The impression one would get of the role of the turbulent flux from examination of phase 1 alone is very different from the conclusion one would derive from examination of phase
3 ; that is, conclusions based on a single wind event are unlikely to be valid for WWBs in general.

The heat flux due to lateral advection, which we have estimated as the residual from the one-dimensional heat budget, behaved similarly. It was large instantaneously but averaged out to near zero. Preliminary estimates of lateral advection from direct measurements (E. Antonissen et al., manuscript in preparation, 1996) agree both qualitatively and quantitatively with our residual during the times when the residual is largest. These results suggest that the effort to estimate the surface flux to within $10 \mathrm{~W} \mathrm{~m}^{-2}$ [Bradley et al., 1993], averaged 
over weeks to months, was successful. Note, though, that this conclusion is tentative, pending final evaluation of lateral fluxes, and also that it applies only to the period of the wind burst. Accurate estimation of the surface flux during low-wind conditions may be intrinsically more difficult [Webster and Lukas, 1992].

Niiler and Stevenson [1982] estimated the average turbulent heat flux across the $28^{\circ} \mathrm{C}$ isotherm in the western Pacific to be $-22 \mathrm{~W} \mathrm{~m}^{-2}$. In our data, this isotherm coincides approximately with the $22 \mathrm{~kg} \mathrm{~m}^{-3}$ isopycnal, across which the average turbulent heat flux was $-18 \mathrm{~W} \mathrm{~m}^{-2}$. The near coincidence of these estimates should not be misinterpreted, though, since the conditions which prevailed during our cruise are not representative of the annual mean. On the one hand, strong winds drove intense mixing in the UOL, thus tending to increase the heat flux into the thermocline. On the other hand, surface cooling acted to decrease the vertical temperature gradient, thus tending to decrease the heat flux into the thermocline. Also, the UOL was relatively deep even before the wind burst began, another factor which favors a weak turbulent heat flux into the thermocline. Nontheless, it seems likely that the first factor was prevalent and that our estimate is therefore best regarded as an upper bound on the climatological mean. During the first leg of the COARE IOP, conditions were more typical and the average turbulent heat flux at the top of the thermocline was negligible Wijesekera and Gregg [1996].

If we suppose that wind burst conditions typically prevail during a total of 2 months of the year, that our value $-18 \mathrm{~W} \mathrm{~m}^{-2}$ for the heat flux at the top of the thermocline is representative of wind burst conditions, and that the heat flux is 0 during the rest of the year (as was the case during leg 1), we can then estimate the annual mean heat flux at the top of the thermocline as $-3 \mathrm{~W} \mathrm{~m}^{-2}$. Assuming Gaussian statistics and an error of $10 \mathrm{~W} \mathrm{~m}^{-2}$ for a 3-week average (see appendix), we obtain an error estimate of $2.5 \mathrm{~W} \mathrm{~m}^{-2}$ for the annual mean. If this scenario is valid, then it is unlikely that mixing into the thermocline could remove more than $6 \mathrm{~W} \mathrm{~m}^{-2}$, on annual average, of heat input at the surface. (On the other hand, wind-driven heat fluxes into the thermocline during boreal summer have not been measured and may be disproportionately large owing to the shallowness of the UOL during that season.)

It therefore appears that Niiler and Stevenson's [1982] estimate of the climatological mean heat flux across the $28^{\circ} \mathrm{C}$ isotherm (which is the same as the surface heat flux averaged over the area enclosed by the isotherm) is too large. The same conclusion applies to other early, large estimates of the heat flux into the warm pool, e.g., Esbensen and Kushnir [1981], $30 \mathrm{~W} \mathrm{~m}^{-2}$; Hsuing [1985], $30 \mathrm{~W} \mathrm{~m}^{-2}$; Weare et al. [1981], $50 \mathrm{~W} \mathrm{~m}^{-2}$; and Reed [1985], $70 \mathrm{~W} \mathrm{~m}^{-2}$. A smaller estimate was obtained by Godfrey and Lindstrom [1989], who applied Pacanowski and Philander's [1981] parameterizations for turbulent fluxes to 24 hours of temperature, salinity, and cur- rent data obtained in the warm pool region. They estimated that the average turbulent heat flux in the upper $100 \mathrm{~m}$ was $10-16 \mathrm{~W} \mathrm{~m}^{-2}$ on the equator and was much smaller than this away from the equator. Gent [1991] has reached a similar conclusion based upon numerical modeling studies, which showed that for a range of wind fields and turbulence parameterizations, the annual mean surface heat flux into the warm pool (most of which was balanced by vertical mixing) is between 0 and $20 \mathrm{~W} \mathrm{~m}^{-2}$.

We have seen that salinity changes are not accounted for by vertical fluxes and therefore appear to have been the result of advection. On short timescales, a patchy distribution of SSS was continuously being advected past our position by the surface current. On longer timescales, equatorial convergence in response to the wind burst worked with the large-scale salinity gradient to advect salty water from south. McPhaden et al. [1992] observed similarly strong salinity advection in a wind burst which occurred late in 1989. In that case, the near-surface region freshened, but it was evident that meridional currents (not precipitation) were responsible for the salinity change. In our case, salinity decreased to the north due to increased precipitation in the Intertropical Convergence Zone (A. Huyer et al., Thermohaline structure of the upper ocean in the COARE intensive flux array. November 1992 to February 1993: an overview, manuscript submitted to Journal of Geophysical Research, 1996), so it appears likely that equatorward currents associated with the dynamic response to the wind burst (SHM1) fluxed saltier water into the COARE region during our cruise.

The restratification of the UOL which occurred in the aftermath of the wind burst is a crucial aspect of the oceanic response. This event affected the temperature and salinity of the sea surface and altered the response to future surface forcing. Restratification was also closely associated with the phytoplankton bloom which was observed following the wind burst [Siegel et al., 1995]; entrainment of nutrients from the thermocline may have triggered the bloom, and the bloom altered the transparency of the upper ocean such as to concentrate solar heating in the top few meters, thereby enhancing stratification. Our one-dimensional budget analyses have indicated that the observed restratification cannot be explained by local mixing alone, and we suggest that it is due in part to advective processes. Analysis of the lateral dependence of the hydrography will be needed in order to understand the relevant physical processes.

\section{Appendix: Uncertainty in Our Estimates of the Turbulent Heat Flux}

In this appendix, we will discuss the method via which the turbulent heat flux at the base of the DML is estimated. Our method combines a variant of the dissipation method [Osborn, 1980] with a residual method 
which is employed when the DML is very shallow. It will be seen that the method requires that we choose values for four undetermined parameters. We will therefore need to estimate not only the turbulent heat flux, but also the uncertainty in the flux estimate due to the arbitrariness in the choice of parameter values.

The turbulent heat flux is expressed as

$$
F_{T}^{h}=-\rho C_{p} K_{T} \frac{\partial T}{\partial z} .
$$

The thermal diffusivity $K_{T}$ is presumed to be equal to the mass diffusivity $K_{\rho}$, and the latter is approximated as

$$
K_{\rho}=\Gamma \frac{\epsilon}{N^{2}},
$$

in accordance with an assumption of production-dissipation balance in the turbulent kinetic energy equation. In the present calculations, $N^{2}$ and $\partial T / \partial z$ are computed from profiles which have been Thorpe-reordered with respect to density [Thorpe, 1977]. The quantity $\Gamma$ is called the mixing efficiency and is usually given the constant value 0.2 , although estimates range from 0.1-0.4 in open ocean studies [Moum, 1990] to 0.7 in a

(a)

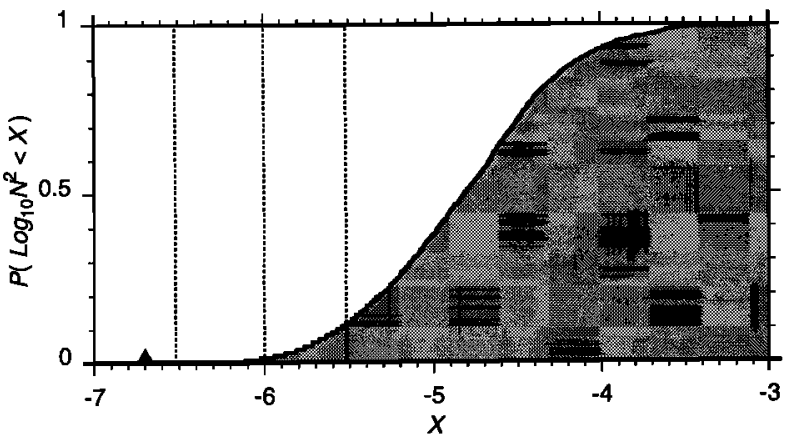

(b)

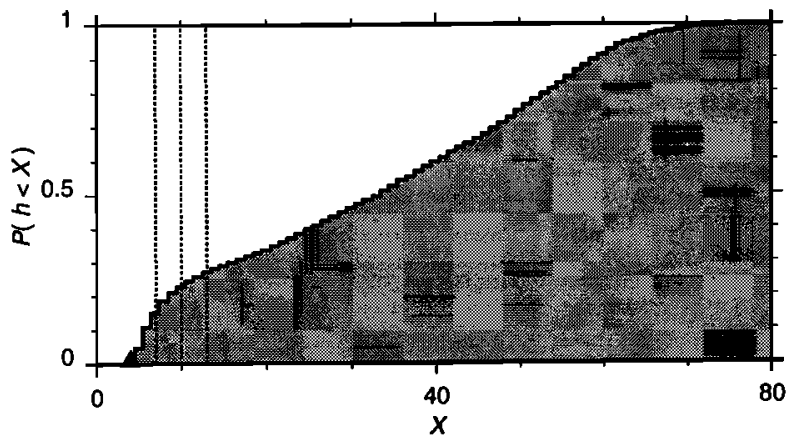

Figure A1. (a) Cumulative probability distribution function for the squared buoyancy frequency at the base of the DML. The vertical density derivative is approximated by a finite difference taken over a 5 -m depth interval whose upper point is the base of the DML. The three vertical dotted lines indicate values for $N_{\min }^{2}$ used in the error analysis. Triangle represents the estimated uncertainty in $N^{2}$. (b) Cumulative probability distribution for $h$, the depth of the DML. Triangle denotes $h=4 \mathrm{~m}$, the minimum value allowed in our calculations. Vertical dotted lines indicate values of $h_{\min }$ used in the error analysis. Both Figures Ala and A1b were computed using results from individual profiles. turbulent tidal front [Gargett and Moum, 1995]. This model seems reasonable in stably stratified turbulence but is singular when $N^{2}$ is 0 . As a result, we must choose an arbitrary minimum value for $N^{2}$, denoted as $N_{\min }^{2}$, below which estimates furnished by the dissipation method will be regarded as invalid. Figure A1a shows a sample cumulative probability distribution of $\log _{10}\left(N^{2}\right)$, with $N^{2}$ given in units of s ${ }^{-2}$, evaluated at the DML base. (Note that $N^{2}$ is nonnegative, since it is computed using Thorpe-reordered density profiles.) The solid triangle in Figure Ala indicates the value $2 \times 10^{-7} \mathrm{~s}^{-2}$, which is the estimated uncertainty in $N^{2}$ due to measurement error. The three vertical dotted lines show possible values for $N_{\text {min }}^{2}$, which we will refer to later in this appendix.

In practice, the vertical derivatives which appear in the expression for $F_{T}^{h}$ must be replaced by differences taken over some finite depth range. Here we take the top of that depth range to be the base of the DML, while the bottom is located at some prescribed distance $\Delta z$ into the stratified fluid below that depth. The depth interval defined by $\Delta z$ is intended to represent the region from which fluid is directly entrained into the DML by turbulent processes. The appropriate value for $\Delta z$ undoubtedly changes from one profile to the next and is likely to be highly dependent on surface forcing, intensity of the local current shear, and other physical factors. However, it is difficult to define this zone, either objectively or subjectively, from profile measurements. Instead, we give $\Delta z$ a constant value, nominally $5 \mathrm{~m}$. Note that there are different problems associated with choosing $\Delta z$ to be too small and choosing it to be too large. Because of the natural intermittency of the turbulence at the mixing layer base, a value of $\Delta z$ which is too small may not include the most energetic events which contribute to the turbulent heat flux. (In a sense, we are averaging in the vertical in an attempt to compensate for undersampling in time.) On the other hand, choosing $\Delta z$ to be too large may result in the inclusion of nonrelevant physics to the computation. While our choice of the value $5 \mathrm{~m}$ is arbitrary, it is based both on considerable investigation of individual profiles and on results from computations made using a wide range of values. Later in this appendix, we will assess the sensitivity of our heat flux estimate to the choice of $\Delta z$.

In this particular experiment, the DML base frequently shallows into the upper few meters of the water column due to a combination of freshwater input at the surface and intense solar heating. Because our profiling measurements are made in the wake of the ship, they are contaminated in the upper few meters. Therefore we do not use the dissipation method when the DML base is shallower than some minimum depth, which we denote as $h_{\min }$. The value of $h_{\min }$ must be chosen arbitrarily; a reasonable choice is $h_{\min }=10 \mathrm{~m}$. The three dotted vertical lines in Figure A1b denote the following three possible values for $h_{\min }: 7,10$, and $13 \mathrm{~m}$, which we will refer to later in this appendix. Choosing $h_{\min }$ in this 
range requires that we reject the heat flux estimate obtained via the dissipation method for between $15 \%$ and $28 \%$ of the profiles taken during the wind burst. This is a serious limitation; instances in which $h<h_{\min }$ are typically sunny afternoons or heavy rain events, i.e., periods in which the heat flux across the base of the DML is expected to be intense. We therefore require an alternative method for estimating $F_{T}^{h}$ when $h<h_{\min }$. We accomplish this by assuming that the one-dimensional heat budget (1) is satisfied identically and compute the turbulent heat flux as a residual; that is,

$$
F_{T}^{h}(-h)=J_{h}^{o}-F_{R}(-h)+\rho c_{p} \int_{-h}^{0} d z \frac{\partial T}{\partial t}
$$

This method should work increasingly well as $h$ approaches zero, since the main term missing from (A3), namely, the lateral advection term, is proportional to $h$. To implement this method, we first average flux estimates obtained via the dissipation method into hourlong bins. Since microstructure profiles are taken every 8-10 min, we typically have six-eight flux estimates in each 1-hour bin. If four or more "good" estimates are available for a given hour, their average is taken as the average flux across the DML base during that hour. Otherwise, hourly averaged values of the surface flux, $\partial T / \partial t$, etc., are substituted into (A3) to yield an estimate for the turbulent flux. Note that this will tend to bring our estimates of the time-averaged residual of the one-dimensional heat budget closer to zero, since that residual is zero by construction during the portion of the time when $h<h_{\min }$.

Finally, there are some occasions in which the UOL is deep enough, during a particular hour, that use of the dissipation method is indicated but less than four good estimates of the heat flux are available. This occurred each day near local noon, for example, when profiling had to be suspended for about an hour due to other operations. In these intervals, the heat flux is estimated via linear interpolation in time. The longest interval in which interpolation was necessary was 7 hours during day 365 , when the conductivity sensors deployed on CHAMELEON failed.

The method described above requires that we choose values for the following four undetermined parameters: (1) the mixing efficiency $\Gamma,(2)$ the minimum of $N^{2}$ for which the dissipation method is regarded as valid $N_{\min }^{2}$, (3) the depth over which finite differences are evaluated $\Delta z$, and (4) the depth above which estimates of $\epsilon$ are assumed to be contaminated by ship wake $h_{\min }$.

In what follows, we will compute the time series of turbulent heat flux across the DML base using a reasonable value for each of these parameters. We will also evaluate the uncertainty in the results due to the arbitrariness in the choice of parameter values. For each of the four parameters, we choose three values: a nominal value which represents our "best" estimate and two other values, one higher than the nominal value and one lower, which are also considered to be within the range of "reasonable" estimates. The choices are as follows: $\Gamma=0.1,0.2,0.3 ; N_{\min }^{2}=3 \times 10^{-7}, 1 \times 10^{-6}, 3 \times 10^{-6} \mathrm{~s}^{-2}$; $\Delta z=3,5,7 \mathrm{~m} ;$ and $h_{\min }=7,10,13 \mathrm{~m}$. The turbulent heat flux has been evaluated for each of the $3^{4}=81$ possible combinations of parameter values, and the results were used to infer uncertainties.

We now examine the results obtained using the nominal value for each parameter, i.e., $\Gamma=0.2, N_{\min }^{2}=$ $1 \times 10^{-6} \mathrm{~s}^{-2}, \Delta z=5 \mathrm{~m}$, and $h_{\min }=10 \mathrm{~m}$. The time series of the turbulent heat flux across the DML base is displayed in Figure A2. Solid circles, open circles, and crosses indicate hourly values obtained using the dissipation method, the residual method, and linear interpolation, respectively. For this parameter set, the dissipation method was employed for $69 \%$ of the hourly estimates. The residual method was employed $16 \%$ of the time, and interpolation was used for the remaining $15 \%$. In general, results obtained using the dissipation method and those obtained as residuals seem reasonably consistent. An exception to this occurs late in day 355, where the residual method yields an anomalously large value. This result is not unreasonable, as an intense squall was encountered during this time. The rainfall during that hour was $33 \mathrm{~mm}$, the largest value measured in the experiment. Surface cooling was intense, the DML was shallow, and it is therefore not surprising that the heat flux across the DML base was large and positive.

In estimating uncertainties due to the arbitrariness of the parameter values given above, we will treat $\Gamma$ separately from the other three parameters. This is because the value of $\Gamma$ is a subject of intensive current research [e.g., Moum and Gargett, 1995] and because the results are much more sensitive to $\Gamma$ than they are to the other parameters. The shaded region on Figure A2 indicates the range of heat flux estimates delivered by the $3^{3}=27$ different combinations of $\Delta z, h_{\text {min }}$, and $N_{\min }^{2}$. The spread in flux estimates is often well in excess of $100 \mathrm{~W} \mathrm{~m}^{-2}$ and tends to be largest when the flux itself is large. Instances of zero spread occur when the DML depth is $<7 \mathrm{~m}$, the smallest value of $h_{\min }$. In these cases, all 27 values are derived via the residual method, which is independent of the values of the four parameters listed. Therefore the 27 estimates are all equal. This does not mean that there is no uncertainty in the estimate of the heat flux; significant errors may be present in the measurements of the quantities appearing on the right-hand side of (A3). However, estimation of these uncertainties would require an analysis of the errors inherent in the meteorological measurements and is therefore beyond the scope of the present work. In addition, the assumption that the one-dimensional heat budget balances may be invalid, particularly on short timescales. An example of this problem occurs early in day 365. During the second hour of that day, the DML base ascended to a depth of $12.5 \mathrm{~m}$. As a result, one third of the heat flux estimates, specifically those employing $h_{\min }=13 \mathrm{~m}$, were obtained using (A3). During 

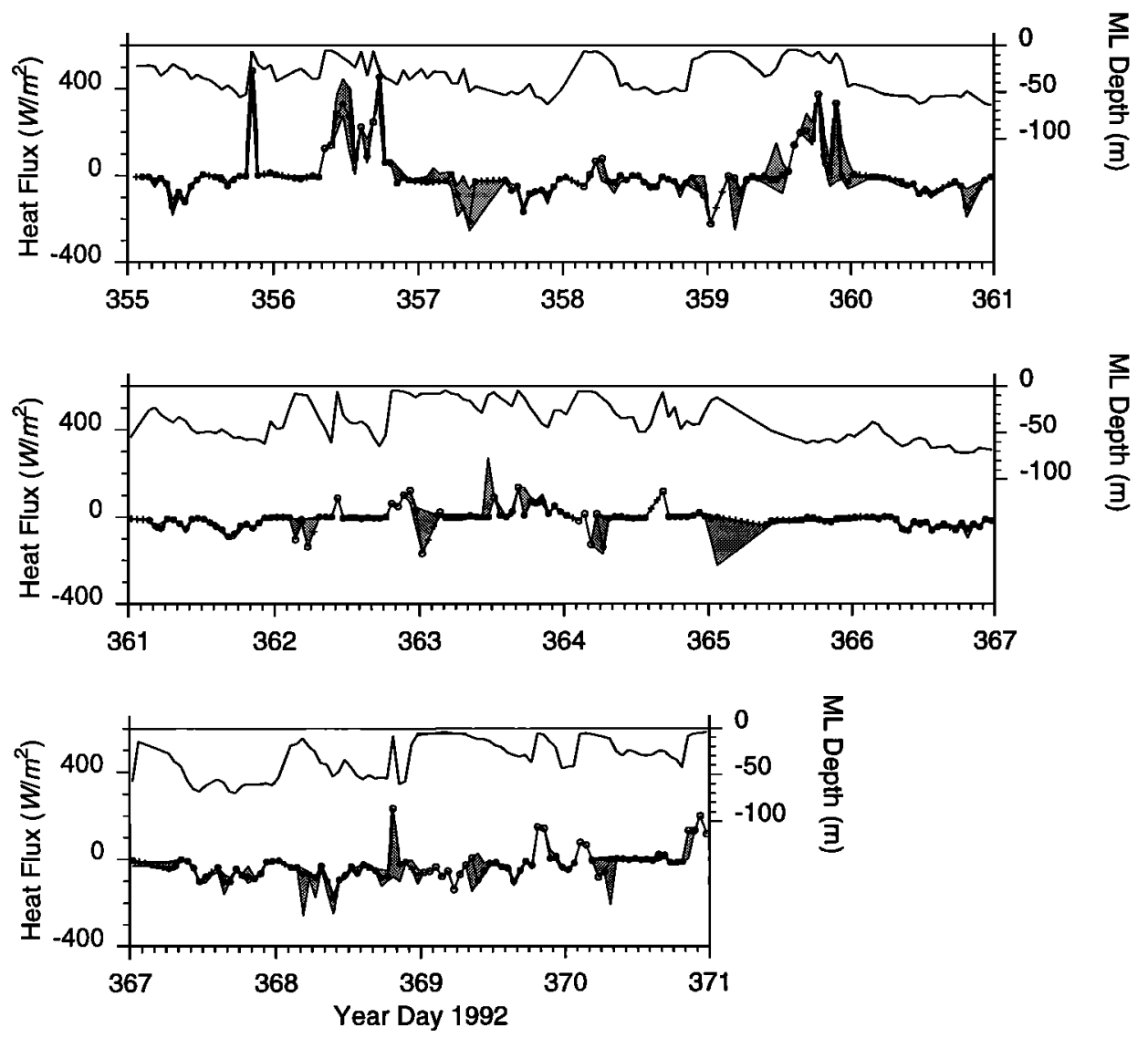

Figure A2. The turbulent heat flux across the DML base. Solid and open circles and crosses indicate hourly values obtained using the dissipation method, the residual method, and linear interpolation, respectively. Also shown is the depth of the DML.

this time, an oceanic cold front passed through the region and the residual method has falsely attributed the observed cooling to the turbulent heat flux. The result is a large negative value for the heat flux. Immediately
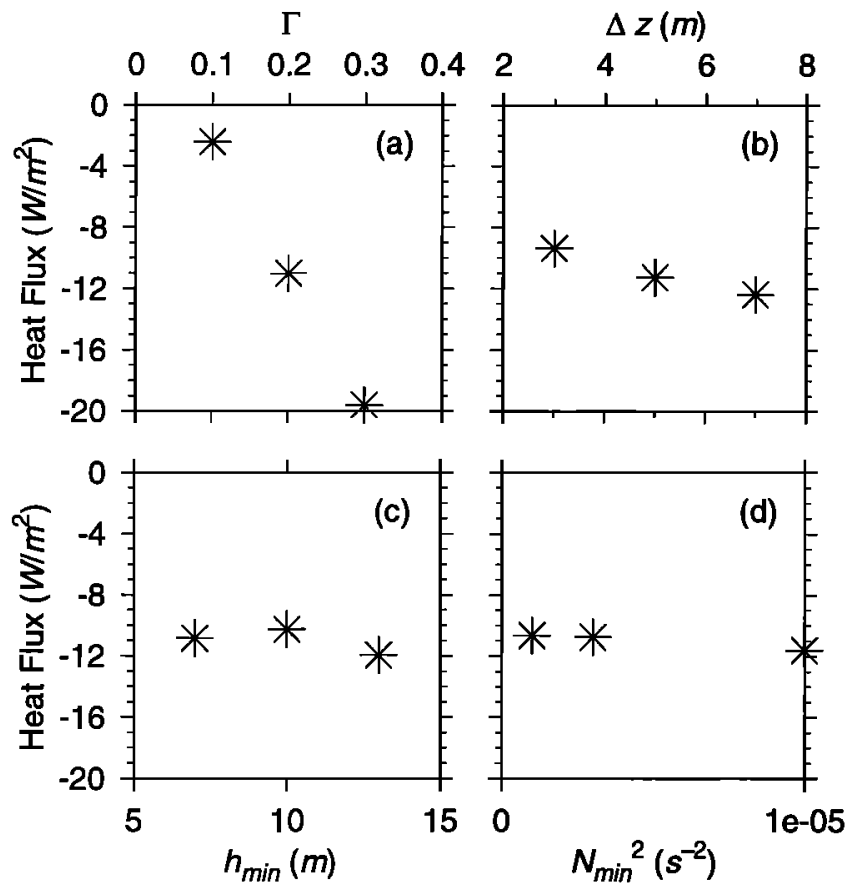

following this, we observe a gap in the data which is filled via interpolation, so that the effect of the anomalous value is seen for several hours. This problem has no effect on our final estimate of the heat flux but will tend to increase our estimate of the uncertainty due to arbitrariness in the value of $h_{\min }$, as it should.

In Figure A3, we summarize the results which are needed to evaluate the importance of the four sources of uncertainty listed above. Figures A3a-A3d each show three estimates of the average turbulent heat flux across the DML base, taken over the duration of the wind

Figure A3. Dependence of the time-averaged turbulent heat flux across the DML base upon the parameters mixing coefficient (a) $\Gamma$, (b) $\Delta z$, (c) $h_{\min }$, and (d) $N_{\min }^{2}$. Three estimates of the average turbulent heat flux across the DML base, taken over the duration of the wind burst, are shown for each parameter. Each estimate is the average of the results from all combinations of parameter values in which a selected parameter has a certain value, the latter value being shown on the abcissa. For example, in Figure A3a, the leftmost asterisk shows that the turbulent heat flux, averaged over the duration of the wind burst and over all 27 combinations of parameter values in which $\Gamma=0.1$, is $-2.4 \mathrm{~W} \mathrm{~m}^{-2}$. The error bars indicate the range of these nine values. 

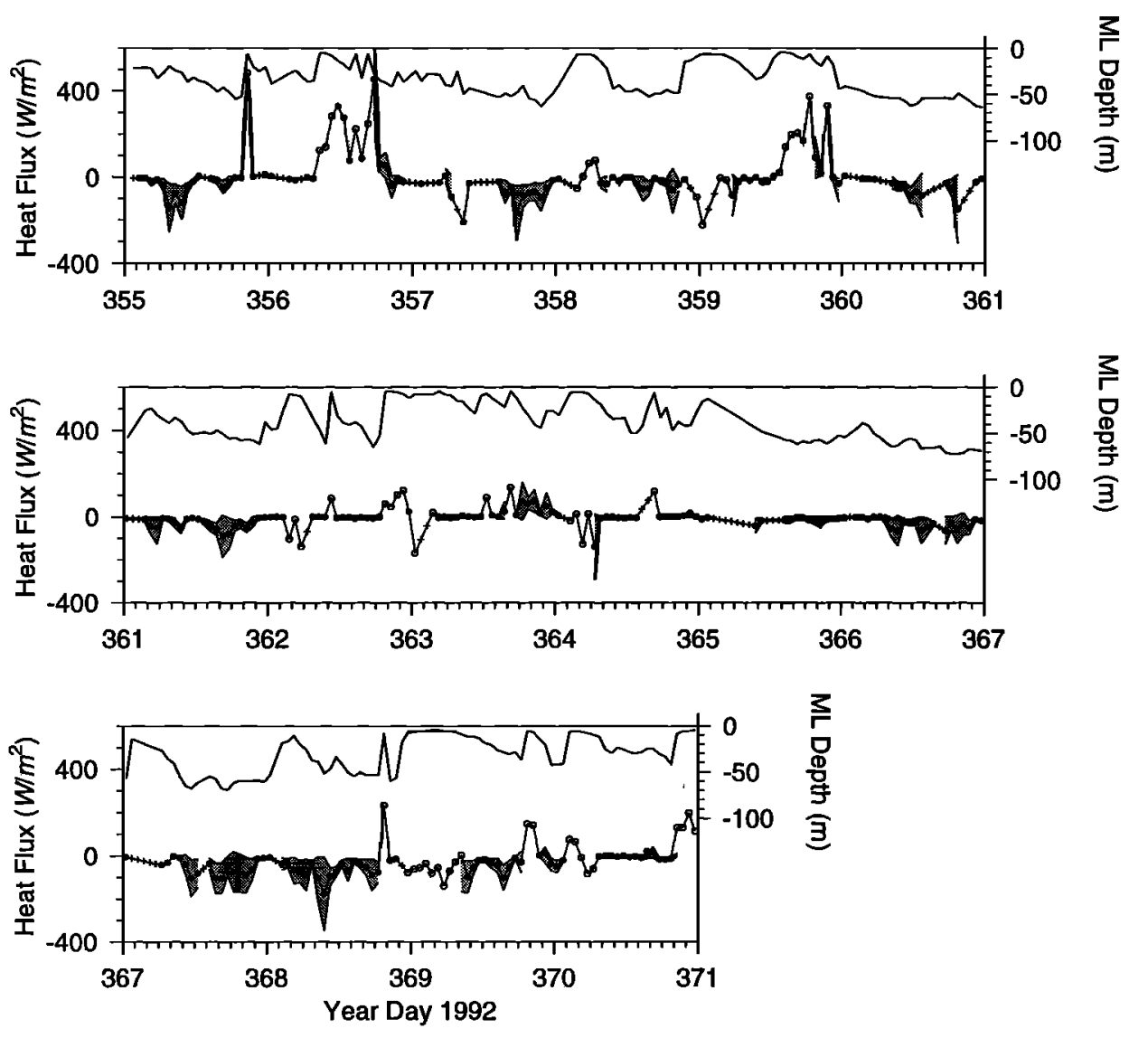

Figure A4. Same as Figure A2, except that gray shading indicates the uncertainty in the hourly mean. We have assumed Gaussian statistics and used twice the standard error in the mean as our estimate of the uncertainty.

burst. Each estimate is the average of the results from all combinations of parameter values in which a selected parameter has a certain value, the latter value being shown on the abcissa.

The time-averaged heat flux for the nominal parameter set $\left(\Gamma=0.2, N_{\min }^{2}=3 \times 10^{-6} \mathrm{~s}^{-2}, \Delta z=5 \mathrm{~m}\right.$, and $\left.h_{\min }=10 \mathrm{~m}\right)$ is $-11 \mathrm{~W} \mathrm{~m}^{-2}$. This represents our best estimate for the average turbulent heat flux during the wind burst. Not surprisingly, the largest uncertainty in this estimate is associated with the choice of $\Gamma$ (see Figure A3a). Increasing that value by 0.1 decreases the heat flux estimate by $8.5 \mathrm{~W} \mathrm{~m}^{-2}$. This is because increasing $\Gamma$ tends to emphasize contributions to the time-averaged heat flux from times when the dissipation method is employed. In those times, the DML is relatively deep and the heat flux is therefore dominated by the downward (negative) flux into the thermocline. In contrast, contributions from times when the residual method is employed tend to be positive, since the DML is shallow during those times and the near-surface flux is upward, on average. Uncertainties associated with the other three parameters appear to be less important; reasonable variations in $N_{\min }^{2}, \Delta z$, and $h_{\min }$ lead to changes in the time-averaged heat flux of $2 \mathrm{~W} \mathrm{~m}^{-2}$ or less.
A second source of uncertainty is due to the fact that we are sampling a highly intermittent quantity at a finite rate. For each hourly estimate of $F_{T}^{h}$ derived using the dissipation method, we have averaged results from between four and eight profiles. In Figure A4, we show the time series of $F_{T}^{h}$ as in Figure A2, with the uncertainty in the hourly mean indicated by gray shading. We have assumed Gaussian statistics and used twice the standard error in the mean as our estimate of the uncertainty. In general, this uncertainty is similar in magnitude to that associated with the arbitrariness of the values of $h_{\min }, \Delta z$, and $N_{\min }^{2}$, as may be seen by comparing Figures B3 and B1. The effect of the finite sampling rate contributes $3 \mathrm{~W} \mathrm{~m}^{-2}$ to the uncertainty in the mean value of $F_{T}^{h}$.

A third source of uncertainty is measurement error. The primary source of measurement error is uncertainty in values of the dissipation rate $\epsilon$, which is generally estimated as a factor of 2 . We therefore assume that each hourly value of the heat flux is uncertain by an amount comparable to the value itself. The RMS value of the turbulent heat flux is $80 \mathrm{~W} \mathrm{~m}^{-2}$. Assuming that each hourly value is uncertain by that amount and that the statistics are roughly Gaussian, the resulting uncertainty in the mean is estimated as $80 \mathrm{~W} \mathrm{~m}^{-2}$ divided by 
the square root of the number of hours in the interval, namely, 383. The result is an uncertainty of $4 \mathrm{~W} \mathrm{~m}^{-2}$.

The net uncertainty in the mean value of $F_{T}^{h}$ due to measurement error, undersampling, and arbitrariness in the values of $h_{\min }, \Delta z$, and $N_{\min }^{2}$ is estimated as $6 \mathrm{~W} \mathrm{~m}^{-2}$. Referring to Figure A3, we note that this combined uncertainty is less than that due to the arbitrariness of $\Gamma$. This further highlights the general problem and topical importance of assessing the mixing efficiency of stratified turbulence in the ocean, as has been emphasized by Gargett and Moum [1995] and Moum and Gargett [1995]. Regarding $\Gamma$ as uncertain by a tolerance of 0.1 , we attach a net uncertainty of $10 \mathrm{~W} \mathrm{~m}^{-2}$ to our estimate of the average turbulent heat flux during the wind burst. Uncertainty in the mean due to the arbitrariness of $\Delta z, h_{\min }$, and $N_{\min }^{2}$ is small. Given that the surface heat flux, estimated from meteorological measurements and averaged over several weeks, is only expected to be accurate to within $10 \mathrm{~W} \mathrm{~m}^{-2}$ [Bradley et al., 1993], we regard this uncertainty as acceptable in the present context. Note, however, that uncertainties in the heat flux averaged over shorter times are significantly larger. The calculations described above have been repeated with respect to the heat flux across the base of the UOL, with nearly identical results.

Acknowledgments. We are grateful to Chris Fairall and George Young for sharing meteorological data and computed fluxes with us; to Mike Gregg for allowing us to use his CTD for daily comparisons with CHAMELEON temperature and conductivity profiles; and to Mike Neeley-Brown, Ray Kreth, Ed and Colleen Llewellyn, Sue Young, Chaojiao Sun, Bill Freer, and Walt Waldorf for engineering and at-sea support for this project. Dave Siegel generously provided ocean transparency data for use in estimating the subsurface radiative heat flux. This work has benefited from discussions with members of the COARE Ocean Heat Budget Subgroup, particularly Meghan Cronin, Eric Antonissen, Hemantha Wijesekera, Stuart Godfrey, Al Plueddemann, Dave Siegel, Carter Ohlmann, and Jane Huyer. This work was supported by the National Science Foundation (OCE 9110552).

\section{References}

Anis, A., and J.N. Moum, The superadiabatic surface layer of the ocean during convection, J. Phys. Oceanogr., 22, 1221-1227, 1992.

Bradley, E. F., J. S. Godfrey, P. A. Coppin, and J. A. Butt, Observations of the net heat flux into the surface mixed layer of the western equatorial Pacific Ocean, J. Geophys. Res., 98, 22,521-22,532, 1993.

Brainerd, K. E., and M.C. Gregg, Surface mixed and mixing layer depths, Deep Sea Res., Part I, 42, (9) 1521-1543, 1995.

Donguy, J., Recent advances in the knowledge of the climatic variations in the tropical Pacific Ocean, Prog. Oceanogr., 19, 49-85, 1987.

Esbensen, S. K., and Y. Kushnir, The heat budget for the global ocean: An atlas based on estimates from surface marine observations, Clim. Res. Inst. Rep., 29, 27 pp., Oreg. State Univ., Corvallis, 1981.
Flament, P., and M. Sawyer, Observations of the effect of rain temperature on the surface heat flux in the Intertropical Convergence Zone, J. Phys. Oceanogr., 25, 413-419, 1995.

Gargett, A. E., and J. N. Moum, Mixing efficiencies in turbulent tidal fronts: Results from direct and indirect measurements of density flux, J. Phys. Oceanogr., 25, 2583$2608,1995$.

Gent, P. R., The heat budget of the TOGA COARE domain in an ocean model, J. Geophys. Res., 96, 3323-3330, 1991.

Godfrey, J. S., and E. J. Lindstrom, The heat budget of the Western Pacific surface mixed layer, J. Geophys. Res., 94, 8007-8017, 1989.

Hsuing, J., Estimates of global meridional heat transport, J. Phys. Oceanogr., 15, 1405-1413, 1985.

Lukas, R., and E. Lindstrom, The mixed layer of the western equatorial Pacific ocean, paper presented at the 'Aha Huliko'a Hawaiian Winter Workshop on the Dynamics of the Oceanic Surface Mixed Layer, Hawaii Inst. of Geophys., Honolulu, 1987.

Lukas, R., and E. Lindstrom, The mixed layer of the western equatorial Pacific ocean, J. Geophys. Res., 96, 3343-3358, 1991.

McPhaden, M. J., F. Bahr, Y. du Penhoat, E. Firing, S. P. Hayes, P. P. Niiler, P. L. Richardson, and J.M. Toole, The response of the western equatorial Pacific ocean to westerly wind bursts during November 1989 to January 1990, J. Geophys. Res., 97, 14,289-14,303, 1992.

Moum, J. N., The quest for $K_{\rho}, J$. Phys. Oceanogr., 20, 1980-1984, 1990.

Moum, J. N., and A. E. Gargett, Mixing efficiencies in stratified fluids: Data from the main thermocline and a turbulent tidal front, paper presented at 11th Symposium on Turbulence and Diffusion, Am. Meteorol. Soc., Boston, Mass., 1995.

Moum, J. N., D. R. Caldwell, and C. A. Paulson, Mixing in the equatorial surface layer and thermocline, J. Geophys. Res., 94, 2005-2021, 1989.

Niiler, P. P., and J. Stevenson, The heat budget of tropical ocean warm-water pools, J. Mar. Res., 40, 465-480, 1982.

Osborn, T. R., Estimates of the local rate of vertical diffusion from dissipation measurements, $J$. Phys. Oceanogr., 10, 83-89, 1980.

Pacanowski, R. C., and S. G. H. Philander, Parameterization of vertical mixing in numerical models of the tropical oceans, J. Phys. Oceanogr., 11, 1443-1451, 1981.

Reed, R. K., An estimate of the climatological heat fluxes over the tropical Pacific Ocean, J. Clım. Appl. Meteorol., 24, 833-840, 1985.

Siegel, D. A., J. C. Ohlmann, L. Washburn, R. R. Bidigare, C. T. Nosse, E. Fields, and Y. Zhou, Solar radiation, phytoplankton pigments and the radiant heating of the equatorial Pacific warm pool, J. Geophys. Res., 100, 4885-4891, 1995.

Smyth, W. D., D. Hebert, and J.N. Moum, Local ocean response to a multiphase westerly wind burst, 1, Dynamic response, J. Geophys. Res., this issue.

Smyth, W. D., P. O. Zavialov, and J.N. Moum, Decay of turbulence in the upper ocean following sudden isolation from surface forcing, $J$. Phys. Oceanogr., in press, 1996.

Thorpe, S. A., Turbulence and mixing in a Scottish loch, Philos. Trans. R. Soc. London, Ser. A, 286, 126-181, 1977.

Weare, B. C., P. T. Strub, and M. D. Samuel, Annual mean surface heat fluxes in the tropical Pacific Ocean, J. Phys. Oceanogr., 11, 705-717, 1981.

Webster, P. J., and R. Lukas, TOGA COARE: The coupled ocean-atmosphere response experiment, Bull. Am. Meteorol. Soc., 73, 1377-1415, 1992. 
Wijesekera, H. W., and M. C. Gregg, Mixing in the western Atmospheric Sciences, Oregon State University, 104 Ocean equatorial Pacific during the first leg of TOGA-COARE, Administration Building, Corvallis, OR 97331. (e-mail: J. Geaphys. Res., 101, 977-998, 1996. smyth@oce.orst.edu)

D. Hebert, Graduate School of Oceanography, University of Rhode Island, Narragansett, RI 02882.

(Received May 30, 1995; revised October 20, 1995;

J. N. Moum and W. D. Smyth, College of Oceanic and accepted December 7, 1995.) 